\title{
An extended hybrid fuzzy multi-criteria decision model for sustainable and resilient supplier selection
}

\author{
Ahmadreza Afrasiabi ${ }^{1} \cdot$ Madjid Tavana $^{2,3}$ (1) $\cdot$ Debora Di Caprio ${ }^{4}$ (i) \\ Received: 12 August 2021 / Accepted: 25 November 2021 / Published online: 20 January 2022 \\ (c) The Author(s), under exclusive licence to Springer-Verlag GmbH Germany, part of Springer Nature 2021
}

\begin{abstract}
The formalization and solution of supplier selection problems (SSPs) based on sustainable (economic, environmental, and social) indicators have become a fundamental tool to perform a strategic analysis of the whole supply chain process and maximize the competitive advantage of firms. Over the last decade, sustainability issues have been often considered in combination with resilient indexes leading to the study of sustainable-resilient supplier selection problems (SRSSPs). The current research on sustainable development, particularly concerned with the strong impact that the recent COVID-19 pandemic has had on supply chains, has been paying increasing attention to the resilience concept and its role within SSPs. This study proposes a hybrid fuzzy multi-criteria decision making (MCDM) method to solve SRSSPs. The fuzzy best-worst method is used first to determine the importance weights of the selection criteria. A combined grey relational analysis and the technique for order of preference by similarity to ideal solution (TOPSIS) method is used next to evaluate the suppliers in a fuzzy environment. Triangular fuzzy numbers (TFNs) are used to express the weights of criteria and alternatives to account for the ambiguity and uncertainty inherent to subjective evaluations. However, the proposed method can be easily extended to other fuzzy settings depending on the uncertainty facing managers and decision-makers. A real-life application is presented to demonstrate the applicability and efficacy of the proposed model. Sixteen evaluation criteria are identified and classified as economic, environmental, social, or resilient. The results obtained through the case study show that "pollution control," "environmental management system," and "risk awareness" are the most influential criteria when studying SRSSPs related to the manufacturing industry. Finally, three different sensitivity analysis methods are applied to validate the robustness of the proposed framework, namely, changing the weights of the criteria, comparing the results with those of other common fuzzy MCDM methods, and changing the components of the principal decision matrix.
\end{abstract}

Keywords Supplier selection $\cdot$ Sustainability $\cdot$ Resilience $\cdot$ Fuzzy logic $\cdot$ Best-worst method $\cdot$ Grey relational analysis . TOPSIS

Responsible Editor: Philippe Garrigues

Madjid Tavana

tavana@lasalle.edu

Ahmadreza Afrasiabi

a.afrasiabi042@gmail.com; a.afrasiabi@uok.ac.ir

Debora Di Caprio

debora.dicaprio@unitn.it

1 Department of Industrial Engineering, University

of Kurdistan, Sanandaj, Iran

\section{Introduction}

The formalization and solution of supplier selection problems (SSPs) based on sustainable (economic, environmental, and social) indicators have become a fundamental tool to perform a strategic analysis of the whole supply chain

2 Business Systems and Analytics Department, La Salle University, Philadelphia, PA, USA

3 Business Information Systems Department, Faculty of Business Administration and Economics, University of Paderborn, Paderborn, Germany

4 Department of Economics and Management, University of Trento, Trento, Italy 
process and maximize the competitive advantage of firms. Corporate executives have become aware of the fact that without an efficient supply chain plan, sooner or later, they will lose any chance to stay or compete in the global marketplace (Torabi et al. 2015; Nayeri et al. 2020, Alamroshan et al. (2021); Fallahpour et al. 2021; Nayeri et al. 2021; Sazvar et al. 2021)

Given the increasing interest shown by consumers and governmental policies in firms' commitment to designing environmentally friendly strategies for production and selling, the investigation of green issues has become the primary point of interest and concern in supply chain management (SCM).

Traditionally, SSPs deal with product cost, delivery time, and quality without considering environmental factors. The implementation of green criteria into the supplier evaluation process has added new dimensions to SSPs and linked them to pollution reduction and waste and ecological damage minimization (Handfield et al. 2002; P. K. Humphreys et al. 2003; P. Humphreys et al. 2006; Kannan et al. 2015).

The supply chain performs well when it considers both the environmental consequences and the possible economic and social benefits that derive from carrying out its specific processes (Zailani et al. 2012). The search for the right balance between environmental and socio-economic factors between and among all stages of the supply chain have made sustainable supplier selection one of the key tools to interpret market demands (Chaabane et al. 2012; Lee et al. 2009; Singh et al. 2014; Lo et al. 2018; Chen et al. 2020; Jain and Singh 2020).

Sustainable choices on the side of supply chain managers represent a meaningful answer to the general concern about the environment and public health that derive from environmental issues related to wastage, toxic gas emissions, increasing environmental pollution, and global warming (Khor and Udin 2013; Alamroshan et al. 2021; Tavana et al. 2021b).

Over the last decade, sustainable aspects have often been combined with the "resilience" concept (Fallahpour et al. 2021), leading to the study of sustainable-resilient supplier selection problems (SRSSPs).

Resilience is defined as the capability to recover quickly and efficiently from disruption (Behzadi et al. 2020). Today's competitive global marketplace is characterized by high levels of uncertainty and chaotic behaviors that unavoidably influence supply chains. These disruptive behaviors are induced by factors such as globalization, demand volatility, an increase in the number of outsourcing activities, reduced product life cycles, drastic reductions in inventories, and a decrease in the number of corporate suppliers. In addition, supply chains face major challenges and threats such as natural disasters (floods, earthquakes, storms, fires, etc.), pandemic diseases (e.g., COVID 19), and so on (Fallahpour et al. 2021).

In general, the disruptions affecting supply chains may be caused by both internal and external threats. Suppliers are one of the primary sources of external threats in supply chain management (SCM) (Rajesh and Ravi 2015). According to statistical reports, raw material costs account for about $65-75 \%$ of production costs (Nazari-Shirkouhi et al. 2013; Alamroshan et al. 2021; Li et al. 2020; Mehrbakhsh and Ghezavati 2020).

Therefore, choosing resilient suppliers can considerably strengthen supply chain processes enhancing both their competitiveness and customer satisfaction through the development of positive risk management skills (Whipple Judith and Roh 2010; Kwak et al. 2018).

Regarding "resilience versus risk," there is an ongoing discussion in the current literature on the differences between resilience and risk and between vulnerability and risk awareness (Linkov et al. 2013b, 2018a, b; Linkov and Trump 2019).

Following Park et al. (2013), we can interpret resilience as "the outcome of a recursive process that includes: sensing, anticipation, learning, and adaptation." A similar cycle is mentioned by Linkov et al. (2013b) for systems designed to provide essential services, with resilience being expressed as the sequence of four abilities: planning/preparing, absorbing, recovering from, and adapting to known and unknown threats (Hollnagel et al. 2011). This leads to the idea of "resilience analysis" as a distinct but complementary process to risk analysis. In this sense, the design of system-specific strategies for achieving resilience represents the key to both operating with the qualitative objectives of the aforementioned cycle and deriving a quantitative counterpart from using in risk analysis.

Linkov and Trump (2019) offer a complete overview of the critical issues that the introduction of the resilience concept has raised both from theoretical and practical viewpoints. Most of these issues concern the correct interpretation of the resilience concept concerning risk analysis and risk management with specific aspects to be considered depending on the field of application (i.e., ecological systems, engineering systems, infrastructure, transportation, manufacturing industry, healthcare, emergency response, communication systems, energy networks, and cybersecurity).

One well-known MCDM approach to the problem of measuring the resilience capacity of a system consists of the resilience matrix tools developed by Linkov et al. (2013a, b). The flexibility of these methodological tools has been validated both at a qualitative and quantitative level by many implementations in different application fields (Roege et al. 2014; Fox-Lent et al. 2015; Linkov and Trump 2019). 
A systematic literature review on supply chain resilience was recently provided by Golan et al. (2020), who see the lack of a comprehensive approach to network resilience as an important gap in the research. A comprehensive approach is needed to account for system components that are usually excluded from the analysis despite being associated with supply chain networks (e.g., transportation, command, and control networks). The relevance of this research gap has been particularly emphasized by the interlinked disruptions generated by the COVID-19 pandemic.

Generally speaking, supplier selection is a MCDM problem in which a finite number of suppliers are assessed against a bounded set of criteria. In particular, the choice of sustainable and resilient suppliers involves identifying and using various criteria that are often in opposition to one another (Memari et al. 2019). Moreover, the supplier selection problems and processes often involve ambiguities and/ or uncertainties because precise values for all the criteria employed in a supplier selection process may not be readily available or accessible (Li et al. 2007; Amid et al. 2006).

This study proposes a comprehensive model that integrates well-defined and robust fuzzy MCDM methods for measuring suppliers based on sustainable and resilient criteria. First, the criteria and sub-criteria are extracted from prior research and thoroughly shaped on the basis of the experts' opinions to fit the sustainable-resilient scenario. Hence, the optimal weights of the finalized criteria and subcriteria are determined by solving a nonlinear optimization model obtained from incorporating the experts' fuzzy evaluations into the fuzzy best-worst method (FBWM). After that, the suppliers are prioritized by using an extended hybrid MCDM method based on grey relational analysis (GRA) and the TOPSIS, both methods being considered within a fuzzy environment. Finally, the robustness of the designed fuzzy MCDM model is evaluated by employing sensitive analysis methods. The main contributions of the present paper can be summarized as follows:

a. presenting an evaluation framework for supplier selection accounting for the resilience concept and the three pillars of sustainability, that is, the economy, the society, and the environment, simultaneously;

b. boosting the use of FBWM as a relatively novel method to assign the weights of the criteria in real-life situations involving ambiguous and/or uncertain data;

iii. developing a combined GRA-TOPSIS approach for applications to sustainable-resilient supplier selection problems (SRSSPs) within the fuzzy settings;

iv. presenting a real-life case study that can guide managers to make effective and sound decisions while considering both sustainability and resilience-related issues.

The rest of the paper is structured as follows. Literature review on supplier selection within a fuzzy environment section reviews some of the recent literature relevant to the present research. Research gasps and motivations section outlines the gaps and the reasons behind the choice of the MCDM methods on which the proposed supplier selection scheme is based. Proposed fuzzy MCDM-based framework section describes the research methodology. Case study section presents the empirical study. Finally, Conclusion and scope of future work section provides a conclusion and offers suggestions for future developments.

\section{Literature review on supplier selection within a fuzzy environment}

Most of the methods proposed over the last two decades to solve economic-based, sustainable-based, and resilientbased SSPs, are MCDM models defined within a fuzzy or grey environment. Fuzzy AHP, fuzzy TOPSIS, grey decision making trial and evaluation laboratory (DEMATEL), and grey simple additive weighting (SAW) are among the most common approaches.

In the following, we provide a brief outline of some of the fuzzy-oriented methods that were recently proposed to solve SSPs.

We start by illustrating the approaches developed within the sustainable context as well as a few extensions to the dynamic supplier selection setting. Hence, we consider some of the research involving resilient factors as the key to interpreting the uncertainty affecting decision makers' (DMs) evaluations. Finally, we focus on the results recently published in the literature on suppliers' performance measurement using a combination of sustainable and resilient criteria.

\section{Sustainable-based supplier selection approaches}

Gupta and Barua (2017) tackled the problem of selecting a green supplier for small and medium-sized enterprises based on the combination of the BWM and fuzzy TOPSIS. Amindoust (2018b) presented a model for supplier selection based on weight restriction fuzzy data envelopment analysis (DEA) by considering sustainability measures. Banaeian et al. (2018) combined fuzzy set theory with the VlseKriterijumska Optimizcija I Kaompromisno Resenje (VIKOR), TOPSIS, and GRA methods to select a green supplier in the agri-food industry. Babbar and Amin (2018) presented a new mathematical model for supplier selection and order quantity allocation using a two-step fuzzy quality function 
deployment (QFD) method and a stochastic multi-objective mathematical model.

Haeri and Rezaei (2019) presented a framework where BWM, fuzzy cognitive mapping, and GRA are integrated to evaluate suppliers based on environmental and economic criteria. Abdullah et al. (2019) used the Preference Ranking Organization Method for Enrichment Evaluation (PROMETHEE) method for evaluating and selecting suppliers based on economic and environmental criteria. Gupta et al. (2019) proposed a hybrid framework where fuzzy Analytic Hierarchy Process (AHP) is used to calculate the criteria weights to incorporate in the Multi-Attributive Border Approximation Area Comparison (MABAC), Weighted Aggregated Sum Product Assessment (WASPAS), and TOPSIS metrics within a fuzzy environment for green supplier selection in the automotive industry. Moheb-Alizadeh and Handfield (2019) proposed a multi-objective, multi-product, multi-period mixed-integer programming model to evaluate suppliers and allocate order quantities while considering sustainability issues along with scarcity and discount conditions. Memari et al. (2019) used TOPSIS and intuitionistic fuzzy set theory to select a reliable supplier for a car spare parts company.

Stević et al. (2020) presented a new MCDM model called Measurement of Alternatives and Ranking according to COmpromise Solution (MARCOS) for sustainable supplier selection problems in the private medical sector. They tested the validity of their proposed model by implementing sensitivity analysis methods.

Mahmoudi et al. (2021a) investigated a sustainable supplier selection problem within a large-scale investment project and combined grey systems theory with the Ordinal Priority Approach (OPA) to consider multiple ranks for criteria and alternatives. Amiri et al. (2021) suggested a model for sustainable supplier selection combining FBWM and $\alpha$-cut analysis. Li et al. (2021) proposed an extended two-stage programming model for selecting a set of suppliers and assigning an order quantity to each supplier in supply chain risk management. In the first stage, they choose potential suppliers based on risk values computed by using BWM. In the second stage, they construct a multi-objective mathematical model for dealing with dynamic sustainable supplier selection and order allocation, simultaneously.

\section{Resilient-based supplier selection approaches}

Parkouhi and Ghadikolaei (2017) presented a two-stage model for selecting resilient suppliers under uncertainty based on the fuzzy analytic network process (ANP) and grey VIKOR techniques. Davoudabadi et al. (2019) introduced a framework based on intuitionistic fuzzy weighted entropy to select resilient suppliers. Parkouhi et al. (2019) proposed a model combining grey theory, DEMATEL, and
SAW methods to select resilient suppliers in uncertain conditions. Davoudabadi et al. (2020) suggested an integrated model for solving resilient supplier selection problems based on fuzzy set theory and a combination of DEA, principal component analysis (PCA), and entropy.

\section{Sustainable- and resilient-based supplier selection approaches}

Sen et al. (2017) considered two sets of green and resilient criteria for supplier selection problems and used the fuzzy TOmada de Decisao Interativa Multicriterio (TODIM) and fuzzy PROMETHEE techniques to rank suppliers. Amindoust (2018a) proposed a hybrid intelligent method for evaluating sustainable-resilient suppliers based on a combined fuzzy inference system (FIS) and DEA approach.

Tirkolaee et al. (2020) developed an integrated decision model where fuzzy ANP, fuzzy DEMATEL, and fuzzy TOPSIS are employed to address SRSSPs in a two-echelon supply chain design. Suppliers' priorities are then used as the inputs of a tri-objective programming model aiming to minimize the total cost, maximize the weighted value of products, and maximize the supply chain's reliability. The multi-objective problem is solved by applying weighted goal programming (WGP).

Among the latest studies, Fallahpour et al. (2021) proposed a hybrid fuzzy decision framework for investigating SRSSPs. They employed an integrated fuzzy DEMATEL, FBWM, and fuzzy ANP approach to weighing the criteria and sub-criteria and FIS to evaluate the suppliers. Mahmoudi et al. (2021b) suggested an extended fuzzy OPA for greenresilient supplier selection problems in the post-COVID-19 era. Tavana et al. (2021a) presented a fuzzy-based approach that combines the fuzzy group BWM and the fuzzy combined compromise solution (FCoCoSo) method for supplier selection in reverse supply chains by considering a LARG (lean, agile, resilient, and green) strategic paradigm.

Table 1 presents a brief schematic review of the studies mentioned above, showing the key features of each study and the corresponding hybrid method.

\section{Research gaps and motivations}

Nowadays, the business environment is affected by a wide range of disruptions that make it more and more difficult to address sustainability and resilience-related issues. Consequently, supply chain managers are often forced to reduce the supply chain sustainability goals and/or deal with inadequate resilience plans. The main challenge for managers has become to design effective supply chains flexible enough to recover from any disruption and allow for sustainability 


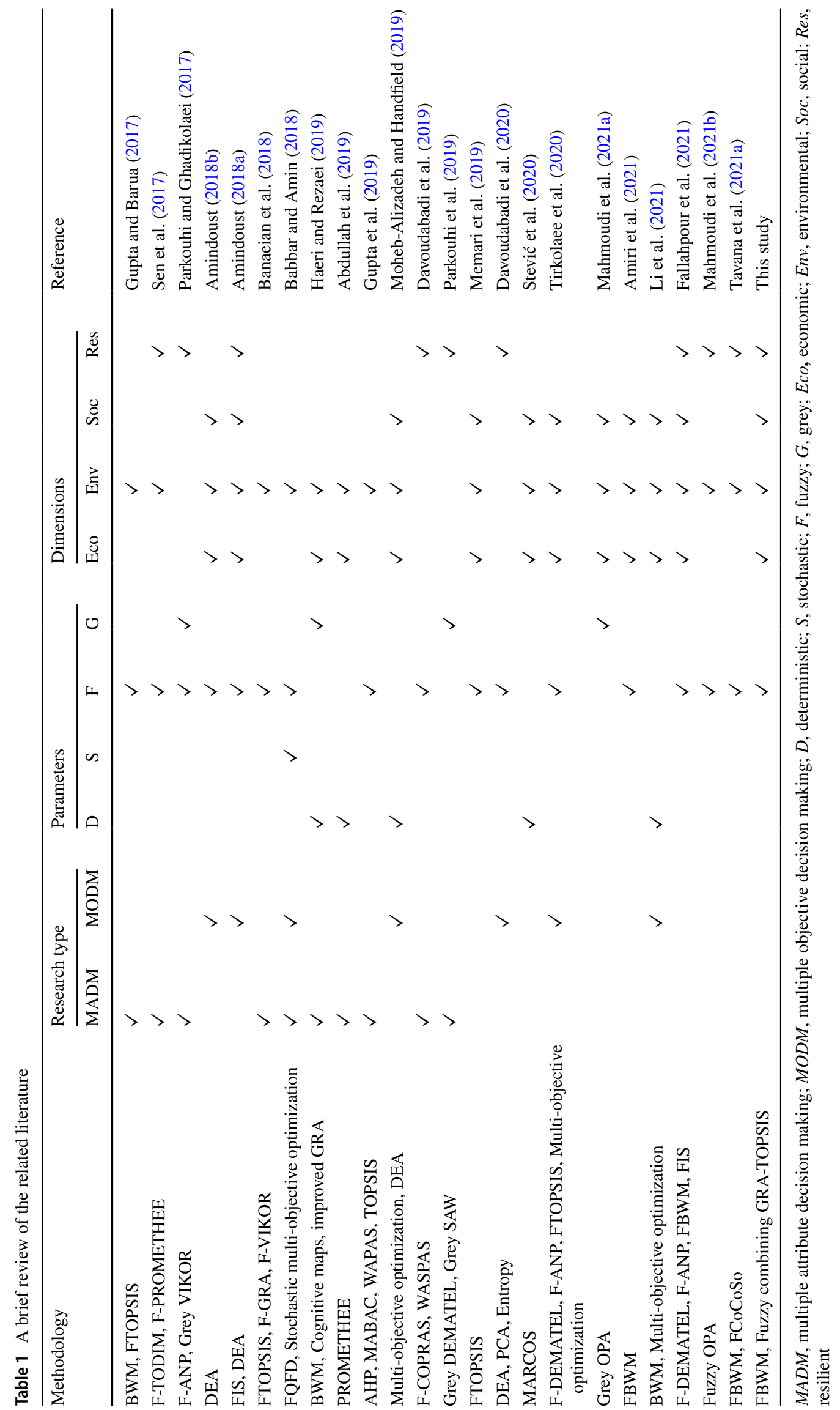


goals to be attained (Fahimnia and Jabbarzadeh 2016; Thomas et al. 2016).

As it can be inferred from the literature review presented in Literature review on supplier selection within a fuzzy environment section, in general, the concepts of sustainability and resilience have been studied independently within the supplier selection setting.

Recent studies have started to consider sustainability and resilience simultaneously, opening the way to an entangled and long-lasting discussion on their similarities and differences. This discussion is basically due to the lack of consensus on the definitions of these two notions and the benefits deriving from their integration within a specific system analysis. In this regard, Marchese et al. (2018) investigate the relationships between sustainability and resilience by performing a structured literature review within the current management contexts. They isolate 37 relevant works organized by application field and classified according to three main frameworks where (1) resilience is considered a component of sustainability, (2) sustainability is considered a component of resilience, or (3) sustainability and resilience are considered separate conceptual objectives (Marchese et al. 2018). In particular, Marchese et al. (2018) find that many research results classifiable as belonging to Framework 2 are concerned with applications to the field of SCM (Ahi and Searcy 2013; Bansal and DesJardine 2014; Closs et al. 2011).

As for the study of sustainability and resilience as described by Framework 3 of Marchese et al. (2018), at the moment, there is only a limited number of research works where these two dimensions are examined simultaneously within a supply chain setting while denoting objectives that must be kept in two different categories (Amindoust 2018a; Sen et al. 2017; Fallahpour et al. 2021). The present research follows the same interpretation for the sustainability and resilience indicators that must be identified to evaluate suppliers' performance.

At the same time, most supplier selection methods include data collection through surveys and sampling. These data are not always available, so in many practical instances, decisions are made based on qualitative data and frequently influenced by the decision maker's subjective opinions in weighing suppliers preferences and criteria (Oztaysi 2014; Zhang et al. 2011; Ansari et al. 2020). There always is a degree of ambiguity and/or uncertainty in decision-making processes that involve subjective evaluations of qualitative or quantitative criteria. This is a significant drawback of all the models focusing on ranking alternatives based on DMs' subjective preferences. For the results of any of these models to be accurate, it is required a lot of knowledge, expertise, and experience ( $\mathrm{Li}$ et al. 2008).

SRSSPs are an example of decision-making processes where criteria are often expressed qualitatively to directly involve
DMs' subjective viewpoint based on their experience and confidence levels. A fuzzy approach to MCDM problems helps compensate for the limitations deriving from the combination of qualitative measures and subjective evaluations.

As shown by the literature review, many MCDA methods can be implemented to rank alternatives within the environmental and engineering research fields. Their validation is usually based on a comparison of the results with those produced by other well-known and widely applied methods. In this regard, Linkov et al. (2021), among others, argue that in many environmental applications, different MCDA methods result in similar prioritization of alternatives.

The similarities among the ranking outcomes provided by different combinations of decision-making tools make one wonder about the necessity of introducing more hybrid models and the convenience of implementing a mathematical structure that, despite being sound, it is inevitably more elaborated than a single procedure repeatedly applied.

Nonetheless, these similarities can be used to validate different and more flexible approaches to decision-making and selection problems. Hybrid models are usually designed so as to allow for (1) the evaluation of criteria and (2) the evaluation of alternatives in two separate moments. They are mostly defined by two subsequent but independent evaluation procedures, with a single link between them consisting of the weights determined for the criteria. This allows researchers to choose which part of a model to focus their attention in developing further analytic tools that improve the accuracy level of results.

All the modifications applied to known methods and the introduction of new techniques aim to reduce the complexity inherent to the carrying out of accurate pairwise comparisons through a case-study-based approach. The combined use of fuzzy set-theoretical notions adds to the construction of feasible and realistically implementable methodologies, eliminating redundant pairwise comparisons.

In an attempt to fill in the research gaps described above, this paper proposes an extended integrated fuzzy decision framework for solving SRSSPs.

Previous studies have extensively investigated the integration of fuzzy set theory with both GRA and TOPSIS. The present study focuses on integrating FBWM and a combined fuzzy GRA-TOPSIS method, which has not yet been presented for assessing suppliers in a sustainable-resilient supply chain network. The reasons behind the choice of these MCDM methods over others are outlined below.

The FBWM, proposed by Guo and Zhao (2017), has the advantage of yielding the weights of criteria by implementing several pairwise comparisons that may be considerably less than the one required by other well-known methods such as AHP and ANP. Both the size of the data set to collect and the computational time decrease. However, this method noticeably reduces the effect of DMs' subjective preferences on the decision-making process. Still, it also yields highly 
consistent results due to a nonlinear optimization model (Guo and Zhao 2017).

The GRA approach, first proposed by Deng (1982), can demonstrate the correlations among a system's reference/optimal level of factors (criteria/alternative). One of the advantages of this approach is that it allows for both qualitative and quantitative relationships between complex factors to be recognized. At the same time, it can investigate the connections between two alternatives through a distance function (Kuo and Liang 2011). In addition to being comprehensible and computationally simple, the GRA method presents certain flexibility that allows for considering different weighting coefficients on the factors being examined (Geum et al. 2011; Lee and Kang 2019; Wu 2002).

The TOPSIS technique was first proposed by Hwang and Yoon (1981) and is one of the most well-known and used approaches to MCDM problems. Based on sound logic that interprets and reflects the rationale of human choice (Kim et al. 1997), TOPSIS utilizes the distance relationship between data series as an evaluation tool. For a deeper discussion about this method, the reader can refer to Gupta and Barua (2017) and Sindhu et al. (2017).

Combining GRA and TOPSIS helps eliminate the shortcomings of both methods and improves the accuracy level of the assessment (Tian et al. 2018a, b). Furthermore, the parallel use of TFNs compensates for the vagueness and uncertainty that characterize DMs' subjective judgments leading to more reliable decision results.

Thus, in the current paper, GRA and TOPSIS are used simultaneously to account for the sensitivity of the proposed selection problem. The integration of GRA and TOPSIS and their simultaneous extension to a fuzzy environment provide a valid framework for determining the most suitable sustainable-resilient supplier according to the characteristics and specific needs of the firm/industry case study under consideration.

The proposed framework has been implemented to analyze a real-life case study at Louleh Manufacturing Company $(\mathrm{LMC})^{1}$, the largest producer of industrial valves, fittings, and pipes in Iran. The results obtained from the case study at LMC show the efficacy of the proposed approach as a manageable tool for evaluating sustainable and resilient suppliers and provide a new contribution to the research on supplier selection.

\section{Proposed fuzzy MCDM-based framework}

We propose an evaluation framework consisting of four phases that are illustrated in Fig. 1. After a preparation phase where the basic choices regarding the experts, the possible suppliers, and the evaluation criteria are made, optimal weights are obtained for the supplier performance indices (economic, environmental, social, and resilient). Hence, the suppliers are ranked to identify the best one,

\footnotetext{
1 The name is changed to protect the anonymity of this manufacturing company.
}

while the ranking results are validated through a sensitivity analysis. These phases are summarized as follows:

- Phase 1 (preparation): Identify a group of experts, suppliers, and the sustainable-resilient criteria and sub-criteria.

- Phase 2 (criteria weight calculation): Calculate the optimal weights of the finalized criteria and sub-criteria by using FBWM.

- Phase 3 (supplier prioritization): Rank all the suppliers by using the combined fuzzy GRA-TOPSIS approach.

- Phase 4 (validation): Validate the ranking results by a sensitivity analysis of different comparison methods.

The rest of this section is dedicated to reviewing some basic definitions concerning fuzzy sets and numbers and briefly describing the steps to perform for each of the MCDM methods involved in the different phases.

\section{Fuzzy sets}

The concepts of fuzzy set and membership function were first proposed by Zadeh (1965). Some basic notions on fuzzy sets and numbers are included below:

\section{Definition 1.}

A fuzzy set A of a universal set $X$ is defined as follows:

$\mathrm{A}=\left\{\left(x, \mu_{\mathrm{A}}(x)\right) \mid x \in X\right\}$

where $\mu_{\mathrm{A}}(x): X \rightarrow[0,1]$ is the membership function of the set A. The membership value $\mu_{\mathrm{A}}(x)$ indicates the degree of membership of $x \in X$ to the $\operatorname{set} A$.

\section{Definition 2.}

A fuzzy set A is called TFN if its membership function is a real function $\mu_{\tilde{A}}(x): \mathbb{R} \rightarrow[0,1]$ defined as follows:

$\mu_{\mathrm{A}}(x)=\left\{\begin{array}{lll}0, & & x \in\left(-\infty, a_{1}\right) \\ & \frac{\left(x-a_{1}\right)}{\left(a_{2}-a_{1}\right)}, & x \in\left[a_{1}, a_{2}\right] \\ & \frac{\left(a_{3}-x\right)}{\left(a_{3}-a_{2}\right)}, & x \in\left[a_{2}, a_{3}\right] \\ 0, & & x \in\left(a_{3},+\infty\right)\end{array}\right.$

where $a_{1} \leq a_{2} \leq a_{3}$. A TFN A is usually denoted by the triple $\left(a_{1}, a_{2}, a_{3}\right)$.

\section{Definition 3.}

Let $A=\left(a_{1}, a_{2}, a_{3}\right)$ and $B=\left(b_{1}, b_{2}, b_{3}\right)$ be two TFNs, and $\beta$ be a fixed number bigger than zero. The following algebraic operations are defined on $A$ and $B$ : 


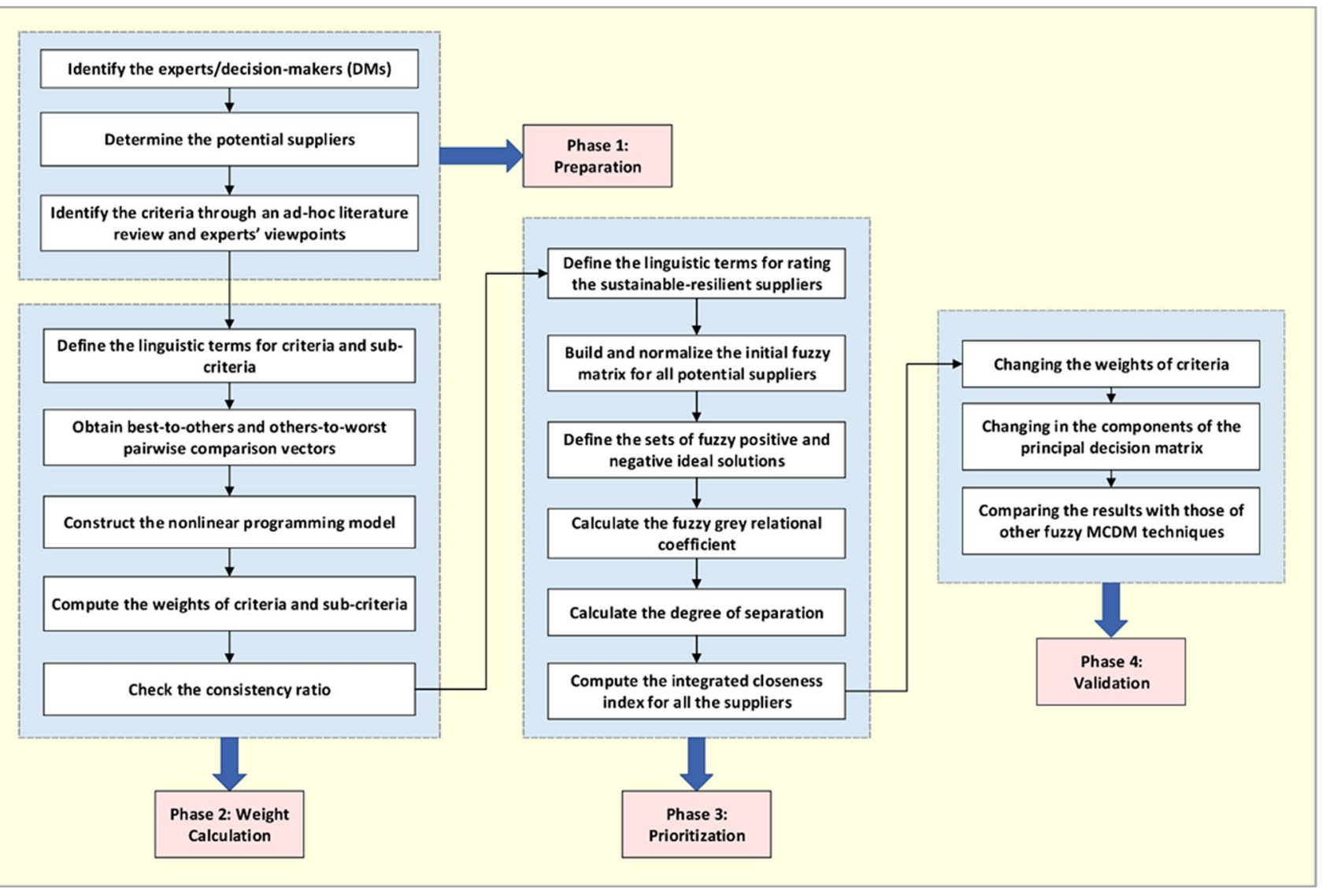

Fig. 1 The proposed framework for evaluating sustainable-resilient suppliers

$\mathrm{A} \oplus \mathrm{B}=\left(a_{1}, a_{2}, a_{3}\right) \oplus\left(b_{1}, b_{2}, b_{3}\right)=\left(a_{1}+b_{1}, a_{2}+b_{2}, a_{3}+b_{3}\right)$

$\mathrm{A} \otimes \mathrm{B}=\left(a_{1}, a_{2}, a_{3}\right) \otimes\left(b_{1}, b_{2}, b_{3}\right)=\left(a_{1} b_{1}, a_{2} b_{2}, a_{3} b_{3}\right)$

$\mathrm{A} \Theta \mathrm{B}=\left(a_{1}, a_{2}, a_{3}\right) \Theta\left(b_{1}, b_{2}, b_{3}\right)=\left(a_{1}-b_{3}, a_{2}-b_{2}, a_{3}-b_{1}\right)$

$\mathrm{A} \oslash \mathrm{B}=\left(a_{1}, a_{2}, a_{3}\right) /\left(b_{1}, b_{2}, b_{3}\right)=\left(a_{1} / b_{3}, a_{2} / b_{2}, a_{3} / b_{1}\right)$

$\beta \mathrm{A}=\left(\beta a_{1}, \beta a_{2}, \beta a_{3}\right)$

Definition 4.

Let $A=\left(a_{1}, a_{2}, a_{3}\right)$ and $B=\left(b_{1}, b_{2}, b_{3}\right)$ be two TFNs. The distance between $A$ and $B$ is defined as the signed distance introduced by Yao and $\mathrm{Wu}(2000)$ :

$d(\mathrm{~A}, \mathrm{~B})$

$=\frac{1}{2} \int_{0}^{1}\left[a_{1}+\left(a_{2}-a_{1}\right) \alpha+a_{3}-\left(a_{3}-a_{2}\right) \alpha-b_{1}-\left(b_{2}-b_{1}\right) \alpha-b_{3}+\left(b_{3}-b_{2}\right) \alpha\right] d \alpha$

Definition 5.
Let $A=\left(a_{1}, a_{2}, a_{3}\right)$ be a TNF. The best non-fuzzy performance $A$ is calculated by the following formula (Liao et al. 2013; Zhao and Guo 2014):

$R(\mathrm{~A})=\frac{1}{6}\left(a_{1}+4 a_{2}+a_{3}\right)$

\section{The fuzzy best-worst method}

Let $\left\{c_{1}, c_{2}, \ldots, c_{n}\right\}$ denote a set of decision criteria. Such a set can be obtained by investigating the existing literature but also taking into account the experts' viewpoint. The steps of FBWM for determining the optimal weights of the criteria $c_{1}$, $c_{2}, \ldots, c_{n}$ are described below.

\section{Linguistic terms for criteria evaluation}

The first step consists in setting the linguistic terms to determine the fuzzy priorities of the criteria. This scale of linguistic terms must be associated with a scale of TFNs and the corresponding consistency indexes (CIs). The CIs will be used to find the consistency ratio (CRs); see also subsection Consistency ratio. 


\section{Fuzzy best-to-others and others-to-worst vectors}

After identifying the best criterion $c_{B}$ and the worst criterion $c_{w}$, the fuzzy priorities of $c_{B}$ over all the other criteria and those of all the criteria over $c_{w}$, can be determined by using the linguistic terms as defined in the previous step. These priorities are used to form the fuzzy best-to-others (BO) vector, $A_{B}$, and the fuzzy others-to-worst (OW) vector, $A_{W}$, as follows:

$\mathrm{A}_{B}=\left(a_{B 1}, a_{B 2}, \ldots, a_{B n}\right)$

$\mathrm{A}_{W}=\left(a_{1 W}, a_{2 W}, \ldots, a_{n W}\right)$

where, for every $j=1,2, \ldots, n, a_{B j}$ indicates the fuzzy preference of the best criterion $c_{B}$ over the $j$-th criterion $c_{j}$ and $a_{j W}$ indicates the fuzzy preference of the $j$-th criterion $c_{j}$ over the worst criterion $c_{w}$.

\section{Nonlinear programming model}

A nonlinear programming model, model (12) below, is obtained based on the components of the $\mathrm{BO}$ and $\mathrm{OW}$ vectors.

s.t. $\left\{\begin{array}{l}\min \xi^{*} \\ \mid \begin{array}{l}\left|\frac{\left(l_{B}^{w}, m_{B}^{w}, u_{B}^{w}\right)}{\left(m_{j}^{w}, m_{j}^{w}, u_{j}^{w}\right)}-\left(l_{B j}, m_{B j}, u_{B j}\right)\right| \leq\left(k^{*}, k^{*}, k^{*}\right) \\ \left|\frac{\left(l_{j}^{w}, m_{j}^{w}, u_{j}^{w}\right)}{\left(w_{W}^{w}, m_{W}^{w}, u_{W}^{w}\right)}-\left(l_{j W}, m_{j W}, u_{j W}\right)\right| \leq\left(k^{*}, k^{*}, k^{*}\right) \\ \sum_{j=1}^{n} R\left(\mathrm{w}_{j}\right)=1 \\ l_{j}^{w} \leq m_{j}^{w} \leq u_{j}^{w} \\ l_{j}^{w} \geq 0 \\ j=1,2, \ldots, n\end{array}\end{array}\right.$

In model (12),

- $a_{B j}=\left(l_{B j}, m_{B j}, u_{B j}\right)$ and $a_{j W}=\left(l_{j W}, m_{j W}, u_{j W}\right)$ represent the $j$-th component of the $\mathrm{BO}$ and $\mathrm{OW}$ vector, respectively;

- $\mathrm{w}_{j}=\left(l_{j}^{w}, m_{j}^{w}, u_{j}^{w}\right), \quad \mathrm{w}_{B}=\left(l_{B}^{w}, m_{B}^{w}, u_{B}^{w}\right), \quad$ a n d $\mathrm{w}_{W}=\left(l_{W}^{w}, m_{W}^{w}, u_{W}^{w}\right)$ are the fuzzy weights of the $j$-th criterion $c_{j}$, the best criterion $c_{B}$ and worst criterion $c_{w}$, respectively;

- $\xi=\left(l^{\xi}, m^{\xi}, u^{\xi}\right)$, with $l^{\xi} \leq m^{\xi} \leq u^{\xi}$, and $\xi^{*}=\left(k^{*}, k^{*}, k^{*}\right)$, with $k^{*} \leq l^{\xi}$.

In general, $l, m$, and $u$ are used to denote the lowest possible, the most probable, and highest possible membership values of a TFN, respectively. Moreover, the constraint $\sum_{j=1}^{n} R\left(\mathrm{w}_{j}\right)=1$ is the translation to the TFN setting of the requirement that the sum of the weights must be 1 . For this condition to be formulated correctly, the fuzzy weights must be defuzzified using Eq. (9).

\section{Optimal fuzzy weights of the criteria}

The optimal fuzzy weights of the criteria $\left(w_{1}^{*}, w_{2}^{*}, \ldots, w_{n}^{*}\right)$ and the optimal value $\xi^{*}$ are obtained solving model (12).

\section{Consistency ratio}

Finally, the consistency ratio (CR) values are computed by the relation $\mathrm{CR}=\xi^{*} / \mathrm{CI}$. The closer is the value of $\mathrm{CR}$ to zero, the higher is the consistency of both the performed pairwise comparisons and the final optimal weights (Tian et al. 2018c).

\section{Implementation in the case study}

For the implementation of phase 2 in the case study, steps 4.2.1. to 4.2.5 are applied to every single DM forming the expert evaluation team separately. Thus, for every DM, model 12 produces the string of optimal fuzzy weights, $\left(w_{1, D M}^{*}, w_{2, D M}^{*}, \ldots, w_{n, D M}^{*}\right)$, and the optimal value $\xi^{* D M}$.

These optimal fuzzy weights are used to define the fuzzy local weights of the main criteria (economic, environmental, social, and resilient) and the sub-criteria identified in phase 1 . The fuzzy local weight of each one of the criteria and subcriteria is calculated by averaging the corresponding components of the optimal fuzzy weights obtained by all the DMs.

Finally, the global optimal fuzzy weight of each sub-criteria is computed by weighting each of the components of its fuzzy local weight by the component of the corresponding main criterion.

\section{The extended GRA-TOPSIS approach}

In this section, an extended decision model is presented to deal with complicated decision-making operations in conditions of information uncertainty. This approach is based on a combination of GRA with TOPSIS, with all the DMs' evaluations being expressed by TFNs.

Let $m$ potential alternatives, $n$ criteria, and $K$ DMs be assigned. The steps of the proposed extended fuzzy GRATOPSIS are described below.

\section{Assign linguistic terms for supplier evaluation}

The first step consists in setting the linguistic terms that must be used to measure each alternative against each criterion. 
As for the criteria evaluation, this scale of linguistic terms must be associated with a scale of TFNs.

\section{Build and normalize the initial fuzzy decision matrix}

The initial fuzzy decision matrix is defined as follows:

$\mathrm{X}=\left[\mathrm{x}_{i j}\right]_{m \times n}$

For every $i=1, \ldots, m$ and $j=1, \ldots, n, x_{i j}$ is the performance degree of the $i$-th alternative with respect to the $j$-th criterion and is computed as follows:

$x_{i j}=\frac{1}{K}\left[x_{i j}^{1}+x_{i j}^{2}+\cdots+x_{i j}^{K}\right]=\frac{1}{K} \sum_{k=1}^{K} x_{i j}^{k}$

where $x_{i j}^{k}$ is the fuzzy rating assigned by the $k$-th DM.

All the elements of $X$ are TFNs, that is, $x_{i j}=\left(l_{i j}, m_{i j}, u_{i j}\right)$, with $i=1, \ldots, m, j=1, \ldots, n$.

The initial fuzzy decision matrix is normalized to guarantee consistency among the evaluation criteria. Hence, the fuzzy normalized-weighted decision matrix is obtained by weighting the normalized matrix elements by the criteria' fuzzy weights. The fuzzy normalized decision matrix $(N)$ and the fuzzy normalized-weighted decision matrix $(Z)$ are defined as follows (Chen 2000):

$\mathrm{N}=\left[x_{i j}^{N}\right]_{m \times n}$

$x_{i j}^{N}= \begin{cases}\left(\frac{l_{i j}}{u_{j}^{+}}, \frac{m_{i j}}{u_{j}^{+}}, \frac{u_{i j}}{u_{j}^{+}}\right), & \text {if } j \in B \\ \left(\frac{l_{j}^{-}}{u_{i j}}, \frac{l_{j}^{-}}{m_{i j}}, \frac{l_{j}^{-}}{l_{i j}}\right), & \text { if } j \in C\end{cases}$

$$
\begin{gathered}
\mathrm{Z}=\left[\mathrm{z}_{i j}\right]_{m \times n} \\
\mathrm{z}_{i j}=\mathrm{z}_{i j} \bullet \mathrm{w}_{j}^{* \text { global }}
\end{gathered}
$$

where

- $B$ and $C$ refer to the sets of beneficial criteria and nonbeneficial criteria, respectively

- for $j \in B, u_{j}^{+}=\max _{i} u_{i j}$,

- for $j \in C, l_{j}^{-}=\min _{i} l_{i j}$,

- $\mathrm{w}_{j}^{* \text { global }}$ is the global optimal fuzzy weight of the $j$-th criterion.

\section{Determine the fuzzy positive and fuzzy negative ideal solutions}

The fuzzy positive ideal solution (FPIS) and fuzzy negative ideal solution (FNIS) are denoted by $\mathrm{Z}^{+}$and $\mathrm{Z}^{-}$, respectively, and determined as shown by Eqs. (16) and (17) below.
$\mathrm{Z}^{+}=\left(\mathrm{z}_{01}^{+}, \mathrm{z}_{02}^{+}, \ldots, \mathrm{z}_{0 n}^{+}\right), \quad \mathrm{z}_{0 j}^{+}=\max _{i}\left(\mathrm{z}_{i j}\right), \quad j=1,2, \ldots, n$

$\mathrm{Z}^{-}=\left(\mathrm{z}_{01}^{-}, \mathrm{z}_{02}^{-}, \ldots, \mathrm{z}_{0 n}^{-}\right), \quad \mathrm{z}_{0 j}^{-}=\min _{i}\left(\mathrm{z}_{i j}\right), \quad j=1,2, \ldots, n$

All the elements of $Z$ are TFNs. Hence, for every $i=1$, $\ldots, m$ and $j=1, \ldots, n$, we have $z_{i j}=\left(z_{i j, l}, z_{i j, m}, z_{i j, u}\right)$, $\mathrm{z}_{0 j}^{+}=\left(z_{0 j, l}^{+}, z_{0 j, m}^{+}, z_{0 j, u}^{+}\right)$, and $\mathrm{z}_{0 j}^{-}=\left(z_{0 j, l}^{-}, z_{0 j, m}^{-}, z_{0 j, u}^{-}\right)$.

\section{Compute the fuzzy grey relational coefficients}

Both the FPIS and FNIS can be considered as reference series against which to compare all the alternatives regarded as series themselves. The fuzzy grey relational coefficient of each alternative with respect to the FPIS and FNIS is calculated through the following equation. Please note that “*” stands for "+" or ".$- "$

$r_{i j}^{*}=\frac{\operatorname{minmin}_{i} d_{i j}^{*}+\rho \operatorname{maxmax}_{i} d_{i j}^{*}}{d_{i j}^{*}+\rho \operatorname{maxmax}_{i} d_{i j}^{*}}$

where, for every $i=1,2, \ldots, m$ and $j=1,2, \ldots, n$, we have

- $r_{i j}^{*}=r\left(\mathrm{z}_{0 j}^{*}, \mathrm{z}_{i j}\right)$ and

- $d_{i j}^{*}=\left|d\left(z_{0, j}^{*}, z_{i j}\right)\right|=\frac{1}{4}\left|\left(z_{0, j, l}^{*}+2 z_{0, j, m}^{*}+z_{0 j, \mu}^{*}\right)-\left(z_{i j, l}+2 z_{i j, m}+z_{i j, u}\right)\right|$.

Note that $d_{i j}^{*}$ is calculated based on the signed distance described in Eq. (8) (Yao and Wu 2000). Moreover, $\rho \in[0,1]$ is the resolution coefficient and is assumed to be equal to 0.5 .

The values $r_{i j}^{*}$ are used to define the grey relational coefficient matrix, $R^{*}=\left[r_{i j}^{*}\right]_{m \times n}$. Then, the grey relation degree of the $i$-th alternative is obtained through Eq. (19).

$R_{i}^{*}=\sum_{j=1}^{n} r_{i j}^{*}, \quad i=1,2, \ldots, m$

\section{Determine the degree of separation of each alternative}

The degree of separation of the $i$-th alternative from FPIS and FNIS is denoted by $D_{i}^{*}$ and computed using Eq. (20) below. Again, please note that "**" indicates "+" or "-."

$D_{i}^{*}=i=1,2, \ldots, m$

\section{Obtain the integrated closeness index}

The normalized values of $R_{i}^{*}$ and $D_{i}^{*}$ are calculated using Eq. (21). As in the previous steps, “*” indicates "+" or “-." 


$$
\overline{\bar{R}}_{i}^{*}=\frac{R_{i}^{*}}{\max _{1 \leq i \leq m} R_{\hat{\imath}}^{*}}, \quad \overline{\bar{D}}_{i}^{*}=\frac{D_{i}^{*}}{\max _{1 \leq i \leq m} D_{\hat{\imath}}^{*}}, \quad i=1,2, \ldots, m
$$

For every $i=1,2, \ldots, m$, the similarity closeness index $(R)$ and distance closeness index $(D)$ of the $i$-th alternative are computed using Eqs. (22) and (23) below:

$$
\begin{aligned}
& \bar{R}_{i}=\frac{\overline{\bar{R}}_{i}^{+}}{\overline{\bar{R}}_{i}^{+}+\overline{\bar{R}}_{i}^{-}}, \quad i=1,2, \ldots, m \\
& \bar{D}_{i}=\frac{\overline{\bar{D}}_{i}^{-}}{\overline{\bar{D}}_{i}^{+}+\overline{\bar{D}}_{i}^{-}}, \quad i=1,2, \ldots, m
\end{aligned}
$$

Clearly, both $R_{i}$ and $D_{i}$ are definite values belonging to $[0,1]$. In order to decrease the effects of subjective biases on the integration process, a nonlinear programming model is used to calculate the final decision index for the single alternatives. This index, also known as the "integrated closeness index," is denoted by $C S_{i}$, with $i=1,2, \ldots, m$, and takes values in the interval $[0,1]$. The larger is the value of $C S_{i}$ the higher is the performance of the $i$-th alternative. The nonlinear programming model is formulated as follows:

$$
\begin{aligned}
& \min \sum_{i=1}^{m}\left[\left(C S_{i}-\mathrm{R}_{i}\right)^{2}+\left(C S_{i}-\mathrm{D}_{i}\right)^{2}\right] \\
& \text { s.t. } \\
& \min \left(\mathrm{R}_{i}, \mathrm{D}_{i}\right) \leq C S_{i} \leq \max \left(\mathrm{R}_{i}, \mathrm{D}_{i}\right) \\
& 0<C S_{i}<1
\end{aligned}
$$

\section{Case study}

This section presents the results obtained from implementing the proposed four-phase methodology to solve the SRSSP within a real-life case study conducted at LMC, the largest producer of industrial valves, fittings, and pipes in Iran.

This section consists of four sub-sections. Each subsection illustrates the results obtained in the corresponding phase of the proposed evaluation framework (see Fig. 1). Phase 1: Identifying sustainable-resilient criteria, experts, and suppliers, introduces the group of experts that have participated in the study, the number of suppliers, and the criteria and sub-criteria that have been identified for the case study. Phase 2: Computing criteria weights using FBWM, shows the results relative to the optimal weights of the evaluation criteria. Phase 3: Prioritizing suppliers using the fuzzy GRA-TOPSIS approach, presents the final priorities obtained for the suppliers. Finally, phase 4: Validating the results illustrates the sensitivity analysis methods used for measuring the robustness of the proposed hybrid framework.
Phase 1: Identifying sustainable-resilient criteria, experts, and suppliers Sustainability- and resilience-based approaches include many quantitative and qualitative dimensions. The key issue is to develop a suitable method for selecting the best supplier by taking into account all sustainable-resilient aspects critical to the real problem being analyzed (Amindoust 2018a).

In the case study, the appropriate criteria and sub-criteria for assessing the suppliers' performance were identified through an extensive review of the prior literature. As already mentioned in section Research gaps and motivations, despite being considered simultaneously, sustainable and resilient aspects were regarded as separate conceptual objectives and, as such, kept in separate categories.

We focused our attention on fairly recent research works involving environmentally friendly and pollution controloriented assessment procedures.

Among the most recent research, Alamroshan et al. (2021) presented a hybrid assessment framework for greenagile SSPs in the medical devices industry. They sorted the evaluation criteria based on traditional (price, quality, flexibility, and technology) and environmental aspects and listed "material cost," "manufacture flexibility," and "environmental performance evaluation" among the criteria with high importance weights. Tavana et al. (2021b) introduced a fuzzy integrated green decision model to assess suppliers in the asphalt manufacturing industry. They identified 14 environmental criteria and grouped them based on four aspects, namely, "pollution controls," "green products," "environmental management," and "pollution production." Fallahpour et al. (2021) designed a fuzzy decision framework to address SRSSPs in the Malaysian palm oil industry. They considered a set of 30 criteria classified as general, sustainable (environmental and social), or resilient. Mohammed et al. (2021) presented a green-resilient supplier assessment framework for SSP in a manufacturing company with 15 criteria being categorized according to traditional, green, and resilient characteristics. Based on their results, resilient criteria have a much higher impact than the other criteria.

Table 2 shows the four main criteria dimensions and the corresponding sub-criteria identified through the literature review. A total of 16 evaluation criteria were classified as economic, environmental, social, and resilient. The references consulted to set this criteria hierarchy are included in the last column of Table 2 .

Note that the resilient sub-criteria identified for the case study related to the ongoing discussions in the current literature on the differences between risk and resilience and between vulnerability and risk awareness (Linkov et al. 2013b; Linkov et al. 2018a, b; Linkov and Trump 2019).

The key points raised by this discussion have already been outlined in Introduction. The names of criteria C13 and C14 
have been slightly changed concerning those used by the cited references (that is, "vulnerability" and "risk awareness") to reflect better the resilience capacity they refer to, which differs from the mere notion of vulnerability or risk awareness.

Finally, three experts were selected and guided through the implementation of the proposed methodology. The experts included a purchasing manager (DM1), a production manager (DM2), and an academician (DM3). They were all knowledgeable in decision-making and had a working experience of almost 20 years at LMC. The experts were asked to evaluate six suppliers: $A_{1}, A_{2}, \ldots, A_{6}$.

Phase 2: Computing criteria weights using FBWM The experts were asked to express their preferences based on their expertise and experience using the linguistic terms in Table 3.

Each expert was asked to determine the best and the worst criterion among the main criteria identified for evaluating the performance of sustainable-resilient suppliers. For instance, the "environmental (Env)" and "economic (Eco)" were chosen as the best and the worst criterion, respectively, by DM1. Then, each expert expressed his/her fuzzy preferences of the best criterion over all the criteria and those relative to all criteria over the worst criterion (still using the linguistic terms presented in Table 3). This led to the definition of the fuzzy BO vector and the fuzzy OW vector. Table 4 reports all the fuzzy preferences expressed by the experts, including their $\mathrm{BO}$ and $\mathrm{OW}$ vectors.

The linguistic terms shown in Table 4 were transformed into TFNs using Table 3. After determining the preference rating of the main criteria, the nonlinear mathematical programming model (model (12)) for obtaining the optimal fuzzy weights was defined and solved for each expert.

To fix the ideas, the calculations relative to model (12) accounting for DM1's evaluations of the main criteria are presented below.

Using TFNs, the $\mathrm{BO}$ and $\mathrm{OW}$ vectors of DM1 were transformed into $\mathrm{A}_{B}=\left[\left(\frac{3}{2}, 2, \frac{5}{2}\right),(1,1,1),\left(\frac{7}{2}, 4, \frac{9}{2}\right),\left(\frac{2}{3}, 1, \frac{3}{2}\right)\right]$ and $\mathrm{A}_{W}=\left[\left(\frac{2}{3}, 1, \frac{3}{2}\right),\left(\frac{7}{2}, 4, \frac{9}{2}\right),(1,1,1),\left(\frac{3}{2}, 2, \frac{5}{2}\right)\right]$, respectively. Thus, model (12) was rewritten for DM1 as follows:

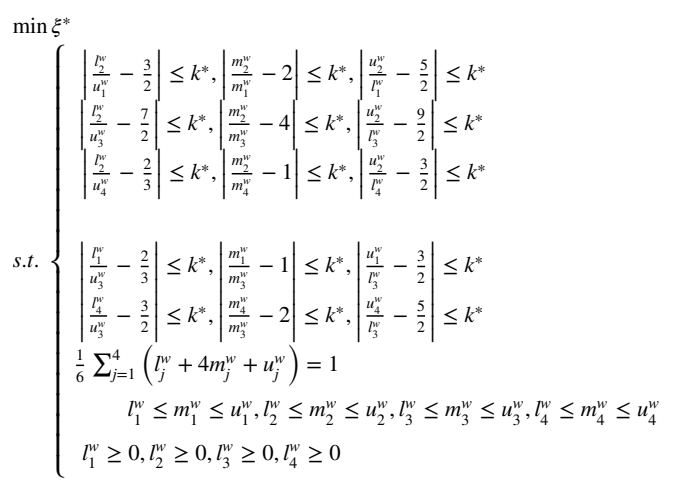

Model (25) was solved with the help of GAMS software producing the following optimal fuzzy weights for the main criteria according to DM1's evaluations:

$\mathrm{w}_{\mathrm{Eco}}^{*}=(0.142,0.180,0.184), \quad \mathrm{w}_{\mathrm{Env}}^{*}=(0.367,0.423,0.423)$,
$\mathrm{w}_{\mathrm{Soc}}^{*}=(0.106,0.121,0.122), \quad \mathrm{w}_{\mathrm{Res}}^{*}=(0.243,0.301,0.316)$,

and the optimal value $\xi^{*}=(0.491,0.491,0.491)$.

Note that $a_{B W}=(7 / 2,4,9 / 2)$. Thus, according to Table 3, the consistency index is equal to 8.04. It follows that the consistency ratio is equal to $0.491 / 8.04=0.061<0.1$. The $\mathrm{CR}$ being close to zero indicates a very high consistency for the fuzzy preference comparisons performed by DM1.

The fuzzy local weights (last columns of Tables 5 and 6 ) were calculated by averaging the corresponding components of the optimal fuzzy weights obtained by all the DMs.

Finally, the global optimal fuzzy weights of the sub-criteria were computed by weighting the components of the fuzzy local weights by those of the main corresponding criteria. These global fuzzy weights and their crisp values are shown in Table 7.

Phase 3: Prioritizing suppliers using the fuzzy GRA-TOPSIS approach The experts were asked to evaluate six suppliers (alternatives) denoted below by $\mathrm{A}_{1}, \mathrm{~A}_{2}, \ldots, \mathrm{A}_{6}$. The initial evaluations were expressed by the experts separately and using the linguistic terms presented in Table 8 .

After converting the linguistic terms in TFNs and obtaining the single experts' ratings of all the suppliers with respect to all the criteria, the average ratings were calculated based on Eq. (13) and the initial fuzzy decision matrix, $X$, constructed as in Eq. (14). The criteria considered in this phase were all the sub-criteria determined in the first phase (Fuzzy sets section). Table 9 shows the initial fuzzy decision matrix obtained with the help of the experts.

The initial fuzzy decision matrix elements were transformed to work with a comparable scale and ensure consistency among the evaluation criteria. Hence, the fuzzy normalized-weighted matrix $Z$ was computed by applying Eq. (15). This matrix is shown in Table 10.

Thus, the reference series given by the FPIS and FNIS were obtained by using Eqs. (16) and (17) and are presented in Table 11.

The fuzzy grey relational coefficient matrix and the grey relation degrees $R_{i}^{+}$and $R_{i}^{-}$of the $i$-th supplier $(i=1,2, \ldots, 6)$ were obtained according to Eqs. (18) and (19), while the degrees of separation $D_{i}^{+}$and $D_{i}^{-}$of the $i$-th supplier $(i=1,2$, ..., 6) from FPIS and FNIS, respectively, were calculated by Eq. (20). Accordingly, the normalized values $\overline{\bar{R}}_{i}^{+}, \overline{\bar{R}}_{i}^{-}, \overline{\bar{D}}_{i}^{+}$, and $\overline{\bar{D}}_{i}^{-}$were also computed using Eq. (21), obtaining: 


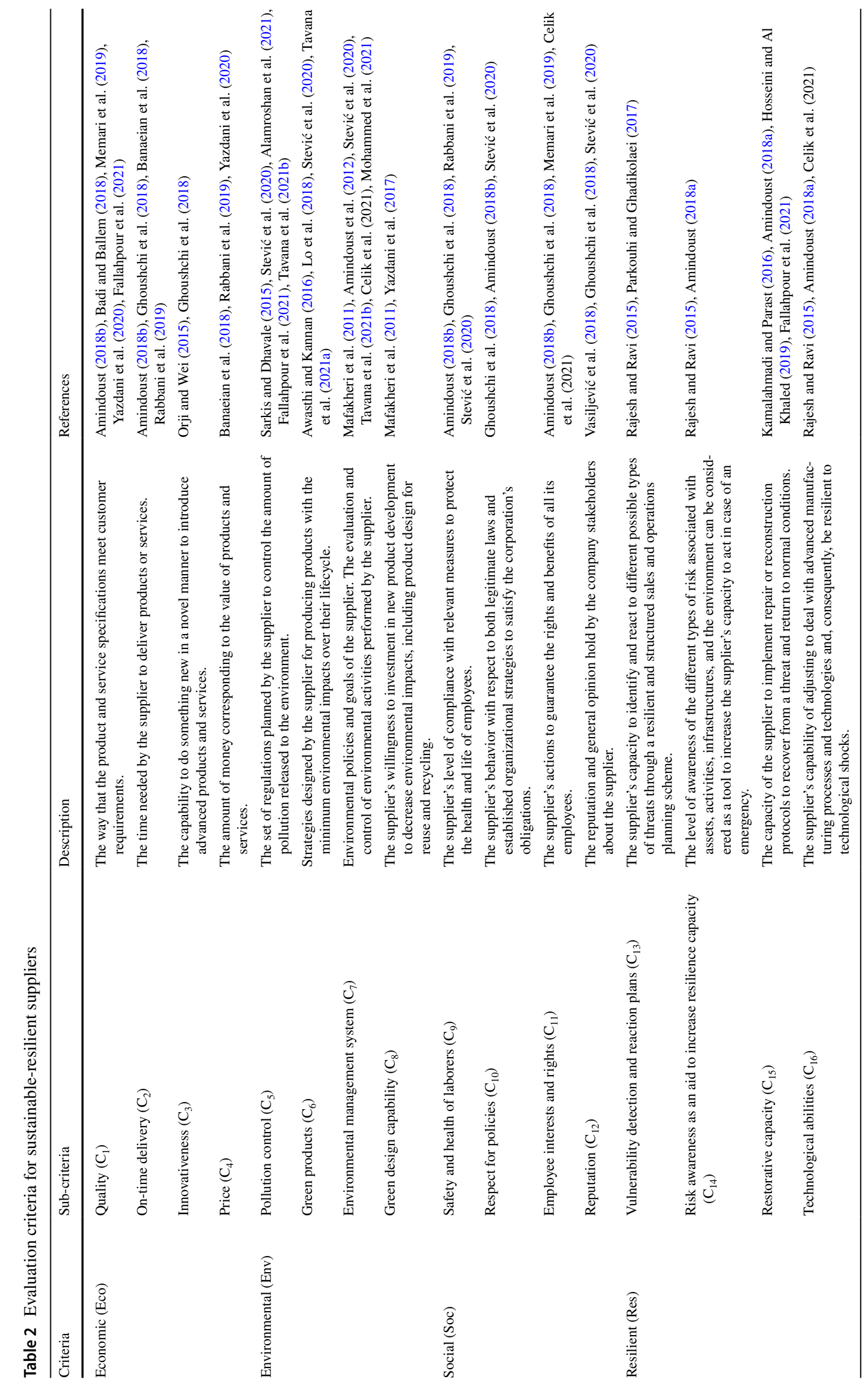


$\left(\overline{\bar{R}}_{1}^{+}, \ldots, \overline{\bar{R}}_{6}^{+}\right)=(0.806,0.876,0.939,0.841,0.853,1.000)$,

$\left(\overline{\bar{R}}_{1}^{-}, \ldots, \overline{\bar{R}}_{6}^{-}\right)=(1.000,0.928,0.876,0.986,0.924,0.804)$,

$\left(\overline{\bar{D}}_{1}^{+}, \ldots, \overline{\bar{D}}_{6}^{+}\right)=(0.905,0.794,0.545,1.000,0.867,0.406)$,

$\left(\overline{\bar{D}}_{1}^{-}, \ldots, \overline{\bar{D}}_{6}^{-}\right)=(0.587,0.756,0.977,0.613,0.533,1.000)$.

The similarity closeness index and the distance closeness index were obtained implementing Eqs. (22) and (23). Finally, the integrated closeness index was acquired using the nonlinear programming model shown in Eq. (24), and the final ranking of the suppliers was obtained. The results were obtained by applying Eqs. (18) to (24) are shown in Table 12. The suppliers were prioritized based on their $C S_{i}$ values, the best supplier is the one exhibiting the highest $C S_{i}$ value. Supplier $\mathrm{A}_{6}$ was ranked first. The final ranking of the six suppliers involved in the case study is as follows:

$\mathrm{A}_{6}>\mathrm{A}_{3}>\mathrm{A}_{2}>\mathrm{A}_{1}>\mathrm{A}_{5}>\mathrm{A}_{4}$

Phase 4: Validating the results The outcomes of MCDM problems can be incorrect or change depending on different circumstances. This may happen, for example, if one or more experts belonging to the evaluation team are replaced by different experts. Therefore, it is important to perform a sensitivity analysis that allows evaluating the robustness of the results (Saaty 2000). Many instances of sensitivity analysis have been considered so far in the operational research and management literature (Behzad et al. 2020). The sensitivity analysis proposed herein for validating the results (the fourth phase of our methodology) consists of the following three parallel procedures: (1) analyzing the effects of changing the weight coefficients on the ranking outcomes; (2) analyzing the effects of changing the components of the principal decision matrix; (3) comparing the results with those obtained by implementing other fuzzy MCDM methods.

\section{Changing the weights of the criteria}

In this section, we describe the sensitivity analysis performed on the results obtained in the case study according to the method suggested by Kahraman (2002) and Kirkwood (1997). Based on this method, a sensitivity analysis of the results of the proposed FBWM-fuzzy GRA-TOPSIS decision model consists of creating new weight vectors and investigating their effects on the final ranking of the suppliers. Sets of new weight vectors are defined in different scenarios that are created using the elasticity weight coefficient. This coefficient allows for relative compensation of all the values of the weight coefficients depending on the variations considered for the weight of the most significant criterion.

As shown in Table 8, the criterion "pollution control $\left(\mathrm{C}_{5}\right)$ " was identified as the most significant criterion since it has the highest crisp weight coefficient, that is, $w_{C_{5}}=0.135$.
Thus, the elasticity weight coefficient of $\mathrm{C}_{5}$, as well as the limits for changing the weight coefficient of $\mathrm{C}_{5}$, were calculated based on the interval $[-0.135,0.866]$.

For the sensitivity analysis, a total of 16 scenarios were set according to the changing limits of the weight coefficient of $\mathrm{C}_{5}$. The new values of the weight coefficients of all the criteria obtained in the 16 scenarios are shown in Table 13. The scenarios are denoted by $\mathrm{S} 1, \ldots, \mathrm{S} 16$.

The method used to obtain the variation interval $[-0.135$, $0.866]$ and the weights of the criteria in the single scenarios are outlined in obtaining the proportionality coefficients of the weights through different scenarios. The interested reader may refer to Kirkwood (1997) and Kahraman (2002) for further details.

These 16 scenarios were examined to evaluate the impact of the weight vectors of the criteria on the final ranking of suppliers. The analysis of the results demonstrated that there is no significant change in the ranking of the suppliers when applying changes to the weight of $\mathrm{C}_{5}$.

The ranking results produced by the 16 scenarios are illustrated in Fig. 2. In all the 16 scenarios, suppliers $A_{6}$ and $\mathrm{A}_{3}$ were the best ranks. In the first three scenarios, there were minor changes in the ranking of the suppliers. In scenario $\mathrm{S} 1$, supplier $\mathrm{A}_{4}$ ranked third, supplier $\mathrm{A}_{5}$ ranked fourth, and supplier $\mathrm{A}_{2}$ ranked fifth. In scenario $\mathrm{S} 2$, compared to scenario $\mathrm{S} 1$, only one change was observed in the third and fourth positions $\left(A_{4}\right.$ and $\left.A_{5}\right)$. In scenario $S 3$, there were slight changes in the ranking of the suppliers: $A_{6}>A_{3}>A_{2}$ $>A_{5}>A_{4}>A_{1}$. These variations did not significantly influence the final results of the model. This fact was also verified by the Spearman correlation coefficient value, whose value was greater than 0.7 for scenarios $\mathrm{S} 1$ to $\mathrm{S} 3$. In the remaining 13 scenarios, the changes made in the weighted vectors had no effect on the final ranking of the suppliers.

For $81.25 \%$ of the scenarios, the ranking results were equal to the initial solution $\left(A_{6}>A_{3}>A_{2}>A_{1}>A_{5}>A_{4}\right)$. Therefore, we can conclude that the ranking obtained using the proposed model is valid and reliable.

A consideration worth making is the following. Being able to determine the weights of the criteria in a purely scientific and logical manner would play a considerable role in the final selection of an optimal sustainable-resilient supplier.

\section{Obtaining the proportionality coefficients of the weights through different scenarios}

The interval $[-0.135,0.866]$ and the changing values of the criteria in each scenario are obtained following the methodology proposed by Kirkwood (1997) and Kahraman (2002) to account for proportionality coefficients of weights during the sensitivity analysis. 
Table 3 Linguistic terms and CI for evaluating sustainable-resilient criteria

\begin{tabular}{|c|c|c|c|c|c|}
\hline Linguistic terms & $\begin{array}{l}\text { Equally impor- } \\
\text { tant (EI) }\end{array}$ & Weakly important (WI) & Fairly important (FI) & Very important (VI) & $\begin{array}{l}\text { Absolutely } \\
\text { important } \\
\text { (AI) }\end{array}$ \\
\hline TFNs & $(1,1,1)$ & $(2 / 3,1,3 / 2)$ & $(3 / 2,2,5 / 2)$ & $(5 / 2,3,7 / 2)$ & $(7 / 2,4,9 / 2)$ \\
\hline CI & 3 & 3.80 & 5.29 & 6.69 & 8.04 \\
\hline
\end{tabular}

Table 4 Best and worst criteria/ sub-criteria and $\mathrm{BO}$ and $\mathrm{OW}$ vectors identified by the experts

\begin{tabular}{|c|c|c|c|c|c|c|c|c|c|c|}
\hline \multirow[t]{2}{*}{ DMs } & \multicolumn{5}{|c|}{ BO vector of the main criteria } & \multicolumn{5}{|c|}{ OW vector of the main criteria } \\
\hline & Best & Eco & Env & Soc & Res & Worst & Eco & Env & Soc & Res \\
\hline DM1 & Env & FI & EI & AI & WI & Soc & WI & AI & EI & FI \\
\hline DM2 & Env & FI & EI & AI & FI & Soc & WI & AI & EI & WI \\
\hline DM3 & Res & AI & FI & FI & EI & Eco & EI & FI & WI & AI \\
\hline \multirow[t]{2}{*}{ DMs } & \multicolumn{5}{|c|}{ BO vector of the economic sub-criteria } & \multicolumn{5}{|c|}{ OW vector of economic sub-criteria } \\
\hline & Best & $\mathrm{C}_{1}$ & $\mathrm{C}_{2}$ & $\mathrm{C}_{3}$ & $\mathrm{C}_{4}$ & Worst & $\mathrm{C}_{1}$ & $\mathrm{C}_{2}$ & $\mathrm{C}_{3}$ & $\mathrm{C}_{4}$ \\
\hline DM1 & $\mathrm{C}_{4}$ & WI & AI & FI & EI & $\mathrm{C}_{2}$ & FI & EI & WI & $\mathrm{AI}$ \\
\hline DM2 & $\mathrm{C}_{1}$ & EI & $\mathrm{AI}$ & FI & FI & $\mathrm{C}_{2}$ & AI & EI & WI & WI \\
\hline DM3 & $\mathrm{C}_{4}$ & WI & WI & VI & EI & $\mathrm{C}_{3}$ & FI & WI & EI & VI \\
\hline \multirow[t]{2}{*}{ DMs } & \multicolumn{5}{|c|}{ BO vector of the environmental sub-criteria } & \multicolumn{5}{|c|}{ OW vector of environmental sub-criteria } \\
\hline & Best & $\mathrm{C}_{5}$ & $\mathrm{C}_{6}$ & $\mathrm{C}_{7}$ & $\mathrm{C}_{8}$ & Worst & $\mathrm{C}_{5}$ & $\mathrm{C}_{6}$ & $\mathrm{C}_{7}$ & $\mathrm{C}_{8}$ \\
\hline DM1 & $\mathrm{C}_{5}$ & EI & AI & FI & WI & $\mathrm{C}_{6}$ & AI & EI & FI & VI \\
\hline DM2 & $\mathrm{C}_{7}$ & WI & VI & EI & WI & $\mathrm{C}_{6}$ & WI & EI & VI & FI \\
\hline DM3 & $\mathrm{C}_{5}$ & EI & FI & FI & AI & $\mathrm{C}_{8}$ & AI & WI & FI & EI \\
\hline \multirow[t]{2}{*}{ DMs } & \multicolumn{5}{|c|}{ BO vector of the social sub-criteria } & \multicolumn{5}{|c|}{ OW vector of social sub-criteria } \\
\hline & Best & $\mathrm{C}_{9}$ & $\mathrm{C}_{10}$ & $\mathrm{C}_{11}$ & $\mathrm{C}_{12}$ & Worst & $\mathrm{C}_{9}$ & $\mathrm{C}_{10}$ & $\mathrm{C}_{11}$ & $\mathrm{C}_{12}$ \\
\hline DM1 & $\mathrm{C}_{9}$ & EI & WI & FI & AI & $\mathrm{C}_{12}$ & AI & FI & FI & EI \\
\hline DM2 & $\mathrm{C}_{11}$ & VI & WI & EI & AI & $\mathrm{C}_{12}$ & FI & FI & AI & EI \\
\hline DM3 & $\mathrm{C}_{9}$ & EI & WI & WI & AI & $\mathrm{C}_{12}$ & $\mathrm{AI}$ & FI & FI & EI \\
\hline \multirow[t]{2}{*}{ DMs } & \multicolumn{5}{|c|}{ BO vector of the resilient sub-criteria } & \multicolumn{5}{|c|}{ OW vector of resilient sub-criteria } \\
\hline & Best & $\mathrm{C}_{13}$ & $\mathrm{C}_{14}$ & $\mathrm{C}_{15}$ & $\mathrm{C}_{16}$ & Worst & $\mathrm{C}_{13}$ & $\mathrm{C}_{14}$ & $\mathrm{C}_{15}$ & $\mathrm{C}_{16}$ \\
\hline DM1 & $\mathrm{C}_{13}$ & EI & WI & VI & WI & $\mathrm{C}_{15}$ & VI & WI & EI & FI \\
\hline DM2 & $\mathrm{C}_{14}$ & FI & EI & AI & FI & $\mathrm{C}_{15}$ & WI & $\mathrm{AI}$ & EI & WI \\
\hline DM3 & $\mathrm{C}_{16}$ & $\mathrm{AI}$ & WI & WI & EI & $\mathrm{C}_{13}$ & EI & FI & FI & $\mathrm{AI}$ \\
\hline
\end{tabular}

Table 5 Relative and local fuzzy weights of the main criteria

\begin{tabular}{lllll}
\hline Main criteria & DM1 & DM2 & DM3 & Fuzzy local weights \\
\hline$\tilde{w}_{\text {Eco }}^{*}$ & $(0.142,0.180,0.184)$ & $(0.165,0.195,0.230)$ & $(0.101,0.121,0.141)$ & $(0.136,0.165,0.185)$ \\
$\tilde{w}_{\text {Env }}^{*}$ & $(0.367,0.423,0.423)$ & $(0.449,0.479,0.479)$ & $(0.210,0.278,0.299)$ & $(0.342,0.393,0.400)$ \\
$\tilde{w}_{\text {Soc }}^{*}$ & $(0.106,0.121,0.122)$ & $(0.118,0.135,0.147)$ & $(0.158,0.176,0.198)$ & $(0.127,0.144,0.156)$ \\
$\tilde{w}_{\text {Res }}^{*}$ & $(0.243,0.301,0.316)$ & $(0.165,0.195,0.230)$ & $(0.431,0.431,0.431)$ & $(0.280,0.309,0.326)$ \\
$C R$ & 0.061 & 0.055 & 0.055 & \\
\hline
\end{tabular}

As mentioned above, the criterion "pollution control $\left(\mathrm{C}_{5}\right)$ " was identified as the most important criterion presenting the highest crisp value among the weight coefficients, $w_{C_{5}}=0.135$.
Following Kirkwood (1997) and Kahraman (2002), the changing limits for criterion $\mathrm{C}_{5}$ were determined by the variable $\Delta x$ whose values vary as follows: 
Table 6 Relative and local fuzzy weights of the sub-criteria

\begin{tabular}{lllll}
\hline Sub-criteria & DM1 & DM2 & DM3 & Fuzzy local weights \\
\hline $\mathrm{C}_{1}$ & $(0.244,0.303,0.318)$ & $(0.467,0.467,0.506)$ & $(0.258,0.258,0.258)$ & $(0.323,0.343,0.361)$ \\
$\mathrm{C}_{2}$ & $(0.106,0.121,0.123)$ & $(0.125,0.132,0.153)$ & $(0.202,0.236,0.258)$ & $(0.144,0.163,0.178)$ \\
$\mathrm{C}_{3}$ & $(0.142,0.171,0.185)$ & $(0.171,0.191,0.243)$ & $(0.125,0.151,0.164)$ & $(0.146,0.171,0.197)$ \\
$\mathrm{C}_{4}$ & $(0.369,0.426,0.426)$ & $(0.171,0.191,0.243)$ & $(0.318,0.368,0.368)$ & $(0.286,0.328,0.346)$ \\
$C R$ & 0.061 & 0.055 & 0.084 & \\
$\mathrm{C}_{5}$ & $(0.319,0.379,0.451)$ & $(0.206,0.240,0.263)$ & $(0.422,0.422,0.457)$ & $(0.316,0.347,0.390)$ \\
$\mathrm{C}_{6}$ & $(0.097,0.097,0.097)$ & $(0.128,0.154,0.167)$ & $(0.155,0.172,0.220)$ & $(0.127,0.141,0.161)$ \\
$\mathrm{C}_{7}$ & $(0.166,0.212,0.248)$ & $(0.324,0.375,0.375)$ & $(0.223,0.272,0.333)$ & $(0.238,0.286,0.319)$ \\
$\mathrm{C}_{8}$ & $(0.263,0.312,0.360)$ & $(0.240,0.240,0.263)$ & $(0.113,0.119,0.138)$ & $(0.205,0.224,0.254)$ \\
$C R$ & 0.026 & 0.084 & 0.055 & \\
$\mathrm{C}_{9}$ & $(0.347,0.404,0.426)$ & $(0.160,0.180,0.180)$ & $(0.345,0.371,0.430)$ & $(0.284,0.318,0.345)$ \\
$\mathrm{C}_{10}$ & $(0.222,0.279,0.310)$ & $(0.245,0.284,0.284)$ & $(0.221,0.256,0.308)$ & $(0.229,0.273,0.301)$ \\
$\mathrm{C}_{11}$ & $(0.208,0.216,0.216)$ & $(0.349,0.443,0.469)$ & $(0.221,0.256,0.308)$ & $(0.259,0.305,0.331)$ \\
$\mathrm{C}_{12}$ & $(0.105,0.114,0.114)$ & $(0.093,0.119,0.119)$ & $(0.105,0.105,0.113)$ & $(0.101,0.113,0.115)$ \\
$C R$ & 0.055 & 0.069 & 0.055 & \\
$\mathrm{C}_{13}$ & $(0.324,0.375,0.375)$ & $(0.165,0.195,0.230)$ & $(0.105,0.105,0.113)$ & $(0.198,0.225,0.239)$ \\
$\mathrm{C}_{14}$ & $(0.206,0.240,0.263)$ & $(0.449,0.479,0.479)$ & $(0.221,0.256,0.308)$ & $(0.292,0.325,0.350)$ \\
$\mathrm{C}_{15}$ & $(0.128,0.154,0.167)$ & $(0.118,0.135,0.147)$ & $(0.221,0.256,0.308)$ & $(0.156,0.182,0.207)$ \\
$\mathrm{C}_{16}$ & $(0.240,0.240,0.263)$ & $(0.165,0.195,0.230)$ & $(0.345,0.371,0.430)$ & $(0.250,0.269,0.308)$ \\
$C R$ & 0.084 & 0.055 & 0.055 & \\
\hline & & & & \\
\hline
\end{tabular}

Table 7 Global weights of evaluation criteria for sustainable-resilient suppliers

\begin{tabular}{|c|c|c|c|c|c|c|}
\hline Main criteria & Main criteria fuzzy local weights & Sub-criteria & Sub-criteria fuzzy local weights & Global fuzzy weights & $\begin{array}{l}\text { Global } \\
\text { crisp } \\
\text { weights }\end{array}$ & Rank \\
\hline \multirow[t]{4}{*}{ Eco } & \multirow[t]{4}{*}{$(0.136,0.165,0.185)$} & $\mathrm{C}_{1}$ & $(0.323,0.343,0.361)$ & $(0.044,0.057,0.067)$ & 0.056 & 8 \\
\hline & & $\mathrm{C}_{2}$ & $(0.144,0.163,0.178)$ & $(0.020,0.027,0.033)$ & 0.027 & 15 \\
\hline & & $\mathrm{C}_{3}$ & $(0.146,0.171,0.197)$ & $(0.020,0.028,0.036)$ & 0.028 & 14 \\
\hline & & $\mathrm{C}_{4}$ & $(0.286,0.328,0.346)$ & $(0.039,0.054,0.064)$ & 0.053 & 10 \\
\hline \multirow[t]{4}{*}{ Env } & \multirow[t]{4}{*}{$(0.342,0.393,0.400)$} & $\mathrm{C}_{5}$ & $(0.316,0.347,0.390)$ & $(0.108,0.136,0.156)$ & 0.135 & 1 \\
\hline & & $\mathrm{C}_{6}$ & $(0.127,0.141,0.161)$ & $(0.043,0.055,0.064)$ & 0.055 & 9 \\
\hline & & $\mathrm{C}_{7}$ & $(0.238,0.286,0.319)$ & $(0.081,0.112,0.128)$ & 0.110 & 2 \\
\hline & & $\mathrm{C}_{8}$ & $(0.205,0.224,0.254)$ & $(0.070,0.088,0.102)$ & 0.087 & 4 \\
\hline \multirow[t]{4}{*}{ Soc } & \multirow[t]{4}{*}{$(0.127,0.144,0.156)$} & $\mathrm{C}_{9}$ & $(0.284,0.318,0.345)$ & $(0.036,0.046,0.054)$ & 0.045 & 11 \\
\hline & & $\mathrm{C}_{10}$ & $(0.229,0.273,0.301)$ & $(0.029,0.039,0.047)$ & 0.039 & 13 \\
\hline & & $\mathrm{C}_{11}$ & $(0.259,0.305,0.331)$ & $(0.033,0.044,0.052)$ & 0.043 & 12 \\
\hline & & $\mathrm{C}_{12}$ & $(0.101,0.113,0.115)$ & $(0.013,0.016,0.018)$ & 0.016 & 16 \\
\hline \multirow[t]{4}{*}{ Res } & \multirow[t]{4}{*}{$(0.280,0.309,0.326)$} & $\mathrm{C}_{13}$ & $(0.198,0.225,0.239)$ & $(0.055,0.070,0.078)$ & 0.068 & 6 \\
\hline & & $\mathrm{C}_{14}$ & $(0.292,0.325,0.350)$ & $(0.082,0.100,0.114)$ & 0.099 & 3 \\
\hline & & $\mathrm{C}_{15}$ & $(0.156,0.182,0.207)$ & $(0.044,0.056,0.067)$ & 0.056 & 7 \\
\hline & & $\mathrm{C}_{16}$ & $(0.250,0.269,0.308)$ & $(0.070,0.083,0.100)$ & 0.084 & 5 \\
\hline
\end{tabular}

Table 8 Linguistic terms to evaluate suppliers' performance

\begin{tabular}{llllll}
\hline $\begin{array}{l}\text { Linguistic } \\
\text { terms }\end{array}$ & $\begin{array}{l}\text { Very low } \\
(\mathrm{VL})\end{array}$ & Low (L) & $\begin{array}{l}\text { Medium } \\
(\mathrm{M})\end{array}$ & High $(\mathrm{H})$ & $\begin{array}{l}\text { Very high } \\
(\mathrm{VH})\end{array}$ \\
\hline TFNs & $(1,1,1)$ & $(2,3,4)$ & $(4,5,6)$ & $(6,7,8)$ & $(8,9,9)$ \\
\hline
\end{tabular}

$$
-w_{s}^{o} \leq \Delta x \leq \min \left\{w_{c}^{o} / \alpha_{c}\right\}
$$

where: 
Table 9 Fuzzy average ratings of the suppliers with respect to the performance criteria

\begin{tabular}{lllllll}
\hline Criteria & $\mathrm{A}_{1}$ & $\mathrm{~A}_{2}$ & $\mathrm{~A}_{3}$ & $\mathrm{~A}_{4}$ & $\mathrm{~A}_{5}$ & $\mathrm{~A}_{6}$ \\
\hline $\mathrm{C}_{1}$ & $(2.33,3.00,3.67)$ & $(3.00,3.67,4.33)$ & $(2.67,3.67,4.67)$ & $(2.00,2.33,2.67)$ & $(3.00,3.67,4.33)$ & $(3.33,4.33,5.33)$ \\
$\mathrm{C}_{2}$ & $(1.67,2.33,3.00)$ & $(3.67,4.33,5.00)$ & $(1.33,1.67,2.00)$ & $(3.33,4.33,5.33)$ & $(3.00,3.67,4.33)$ & $(2.33,3.00,3.67)$ \\
$\mathrm{C}_{3}$ & $(2.33,3.00,3.67)$ & $(2.67,3.67,5.00)$ & $(4.00,5.00,6.00)$ & $(3.67,4.33,5.00)$ & $(3.33,4.33,5.33)$ & $(3.67,4.33,5.00)$ \\
$\mathrm{C}_{4}$ & $(2.67,3.67,4.67)$ & $(3.33,4.33,5.33)$ & $(4.67,5.67,6.67)$ & $(5.33,6.33,7.67)$ & $(1.33,1.67,2.00)$ & $(2.00,2.33,2.67)$ \\
$\mathrm{C}_{5}$ & $(3.33,4.33,5.33)$ & $(4.00,5.00,6.00)$ & $(5.00,5.67,6.00)$ & $(1.33,1.67,2.00)$ & $(2.00,2.33,2.67)$ & $(4.67,5.67,6.67)$ \\
$\mathrm{C}_{6}$ & $(2.00,2.33,2.67)$ & $(1.67,2.33,3.00)$ & $(1.67,2.33,3.00)$ & $(4.67,5.67,7.00)$ & $(3.33,4.33,5.33)$ & $(6.00,7.00,7.67)$ \\
$\mathrm{C}_{7}$ & $(2.00,2.33,2.67)$ & $(1.67,2.33,3.00)$ & $(5.33,6.33,7.33)$ & $(4.67,5.67,6.67)$ & $(3.33,4.33,5.33)$ & $(3.67,4.33,5.00)$ \\
$\mathrm{C}_{8}$ & $(3.00,3.67,4.33)$ & $(4.00,5.00,6.00)$ & $(5.33,6.33,7.33)$ & $(5.33,6.33,7.33)$ & $(3.33,4.33,5.33)$ & $(6.00,7.00,7.67)$ \\
$\mathrm{C}_{9}$ & $(2.00,2.33,2.67)$ & $(2.00,3.00,4.00)$ & $(4.00,5.00,6.00)$ & $(2.67,3.67,4.67)$ & $(3.67,4.33,4.76)$ & $(4.33,5.00,5.33)$ \\
$\mathrm{C}_{10}$ & $(3.00,3.67,4.33)$ & $(4.67,5.67,6.67)$ & $(3.33,4.33,5.33)$ & $(2.00,2.33,2.67)$ & $(2.33,3.00,3.67)$ & $(3.33,4.33,5.33)$ \\
$\mathrm{C}_{11}$ & $(2.33,3.00,3.67)$ & $(2.33,3.00,3.67)$ & $(2.67,3.67,4.67)$ & $(4.00,5.00,6.00)$ & $(1.67,2.33,3.00)$ & $(5.33,6.33,7.00)$ \\
$\mathrm{C}_{12}$ & $(3.33,4.33,5.33)$ & $(2.33,3.00,3.67)$ & $(5.33,6.33,7.33)$ & $(2.33,3.00,3.67)$ & $(2.67,3.00,3.33)$ & $(4.33,5.00,5.67)$ \\
$\mathrm{C}_{13}$ & $(2.33,3.00,3.67)$ & $(5.00,5.67,6.00)$ & $(4.00,5.00,6.00)$ & $(5.33,6.33,7.33)$ & $(3.00,3.67,4.33)$ & $(3.67,4.33,4.67)$ \\
$\mathrm{C}_{14}$ & $(3.33,4.33,5.33)$ & $(4.67,5.67,6.67)$ & $(5.33,6.33,7.00)$ & $(4.67,5.67,6.67)$ & $(4.67,5.67,6.33)$ & $(3.67,4.33,4.67)$ \\
$\mathrm{C}_{15}$ & $(2.33,3.00,3.67)$ & $(5.33,6.33,7.33)$ & $(5.00,5.67,6.00)$ & $(1.33,1.67,2.00)$ & $(2.00,2.33,2.67)$ & $(5.33,6.33,7.00)$ \\
$\mathrm{C}_{16}$ & $(4.67,5.67,6.67)$ & $(4.00,5.00,6.00)$ & $(4.67,5.67,6.67)$ & $(2.67,3.67,4.67)$ & $(3.33,4.33,5.33)$ & $(4.67,5.67,6.67)$ \\
\hline
\end{tabular}

Table 10 The normalized-weighted decision matrix

\begin{tabular}{llllllll}
\hline Criteria & $\mathrm{A}_{1}$ & $\mathrm{~A}_{2}$ & $\mathrm{~A}_{3}$ & $\mathrm{~A}_{4}$ & $\mathrm{~A}_{5}$ & $\mathrm{~A}_{6}$ \\
\hline $\mathrm{C}_{1}$ & $(0.019,0.032,0.046)$ & $(0.025,0.039,0.054)$ & $(0.022,0.039,0.058)$ & $(0.016,0.025,0.033)$ & $(0.025,0.039,0.054)$ & $(0.027,0.046,0.067)$ \\
$\mathrm{C}_{2}$ & $(0.006,0.012,0.019)$ & $(0.013,0.022,0.031)$ & $(0.005,0.008,0.012)$ & $(0.012,0.022,0.033)$ & $(0.011,0.018,0.027)$ & $(0.009,0.015,0.023)$ \\
$\mathrm{C}_{3}$ & $(0.008,0.014,0.022)$ & $(0.009,0.017,0.030)$ & $(0.013,0.024,0.036)$ & $(0.012,0.020,0.030)$ & $(0.011,0.020,0.032)$ & $(0.012,0.020,0.030)$ \\
$\mathrm{C}_{4}$ & $(0.011,0.020,0.032)$ & $(0.010,0.017,0.026)$ & $(0.008,0.013,0.018)$ & $(0.007,0.011,0.016)$ & $(0.026,0.043,0.064)$ & $(0.019,0.031,0.043)$ \\
$\mathrm{C}_{5}$ & $(0.054,0.089,0.125)$ & $(0.065,0.102,0.140)$ & $(0.081,0.116,0.140)$ & $(0.022,0.034,0.047)$ & $(0.032,0.048,0.062)$ & $(0.076,0.116,0.156)$ \\
$\mathrm{C}_{6}$ & $(0.011,0.017,0.022)$ & $(0.009,0.017,0.025)$ & $(0.009,0.017,0.025)$ & $(0.026,0.041,0.059)$ & $(0.019,0.031,0.045)$ & $(0.034,0.051,0.064)$ \\
$\mathrm{C}_{7}$ & $(0.022,0.036,0.046)$ & $(0.018,0.036,0.052)$ & $(0.059,0.097,0.128)$ & $(0.052,0.087,0.116)$ & $(0.037,0.066,0.093)$ & $(0.041,0.066,0.087)$ \\
$\mathrm{C}_{8}$ & $(0.027,0.042,0.057)$ & $(0.037,0.057,0.080)$ & $(0.049,0.073,0.097)$ & $(0.049,0.073,0.097)$ & $(0.030,0.050,0.071)$ & $(0.055,0.080,0.102)$ \\
$\mathrm{C}_{9}$ & $(0.012,0.018,0.024)$ & $(0.012,0.023,0.036)$ & $(0.024,0.038,0.054)$ & $(0.016,0.028,0.042)$ & $(0.022,0.033,0.042)$ & $(0.026,0.038,0.048)$ \\
$\mathrm{C}_{10}$ & $(0.013,0.022,0.031)$ & $(0.020,0.033,0.047)$ & $(0.015,0.026,0.038)$ & $(0.009,0.014,0.019)$ & $(0.010,0.018,0.026)$ & $(0.015,0.026,0.038)$ \\
$\mathrm{C}_{11}$ & $(0.011,0.019,0.027)$ & $(0.011,0.019,0.027)$ & $(0.013,0.023,0.034)$ & $(0.019,0.031,0.044)$ & $(0.008,0.015,0.022)$ & $(0.025,0.040,0.052)$ \\
$\mathrm{C}_{12}$ & $(0.006,0.010,0.013)$ & $(0.004,0.007,0.009)$ & $(0.009,0.014,0.018)$ & $(0.004,0.007,0.009)$ & $(0.005,0.007,0.008)$ & $(0.008,0.011,0.014)$ \\
$\mathrm{C}_{13}$ & $(0.035,0.054,0.078)$ & $(0.022,0.029,0.036)$ & $(0.022,0.032,0.045)$ & $(0.018,0.026,0.034)$ & $(0.030,0.044,0.061)$ & $(0.028,0.037,0.050)$ \\
$\mathrm{C}_{14}$ & $(0.041,0.065,0.091)$ & $(0.057,0.085,0.114)$ & $(0.041,0.065,0.091)$ & $(0.057,0.085,0.114)$ & $(0.057,0.085,0.108)$ & $(0.045,0.065,0.080)$ \\
$\mathrm{C}_{15}$ & $(0.014,0.023,0.034)$ & $(0.032,0.049,0.067)$ & $(0.030,0.043,0.055)$ & $(0.008,0.013,0.018)$ & $(0.012,0.018,0.025)$ & $(0.032,0.049,0.067)$ \\
$\mathrm{C}_{16}$ & $(0.049,0.071,0.100)$ & $(0.042,0.062,0.090)$ & $(0.049,0.071,0.100)$ & $(0.028,0.046,0.070)$ & $(0.035,0.045,0.080)$ & $(0.049,0.071,0.090)$ \\
\hline
\end{tabular}

$w_{s}^{o}$ represents the original values of the weight of the most important criterion (the reference value),

$w_{c}^{o}$ represents the original values of the weights of the criteria, and

$\alpha_{c}$ expresses the relative compensation of the values of the weight coefficients in relation to the given changes in the weight of the most important criterion, and it is calculated as follows:

$$
\alpha_{c}=w_{c}^{o} / \Sigma_{c}^{o}
$$


Table 11 FPIS and FNIS as reference series

\begin{tabular}{lll}
\hline Criteria & $\tilde{Z}^{+}$ & $\tilde{Z}^{-}$ \\
\hline $\mathrm{C}_{1}$ & $(0.027,0.046,0.067)$ & $(0.016,0.025,0.033)$ \\
$\mathrm{C}_{2}$ & $(0.013,0.022,0.033)$ & $(0.005,0.008,0.012)$ \\
$\mathrm{C}_{3}$ & $(0.013,0.024,0.036)$ & $(0.008,0.014,0.022)$ \\
$\mathrm{C}_{4}$ & $(0.026,0.043,0.064)$ & $(0.007,0.011,0.016)$ \\
$\mathrm{C}_{5}$ & $(0.081,0.116,0.156)$ & $(0.022,0.034,0.047)$ \\
$\mathrm{C}_{6}$ & $(0.034,0.051,0.064)$ & $(0.009,0.017,0.022)$ \\
$\mathrm{C}_{7}$ & $(0.059,0.097,0.128)$ & $(0.018,0.036,0.046)$ \\
$\mathrm{C}_{8}$ & $(0.055,0.080,0.102)$ & $(0.027,0.042,0.057)$ \\
$\mathrm{C}_{9}$ & $(0.026,0.038,0.054)$ & $(0.012,0.018,0.024)$ \\
$\mathrm{C}_{10}$ & $(0.020,0.033,0.047)$ & $(0.009,0.014,0.019)$ \\
$\mathrm{C}_{11}$ & $(0.025,0.040,0.052)$ & $(0.008,0.015,0.022)$ \\
$\mathrm{C}_{12}$ & $(0.009,0.014,0.018)$ & $(0.004,0.007,0.008)$ \\
$\mathrm{C}_{13}$ & $(0.035,0.054,0.078)$ & $(0.018,0.026,0.034)$ \\
$\mathrm{C}_{14}$ & $(0.057,0.085,0.114)$ & $(0.041,0.065,0.080)$ \\
$\mathrm{C}_{15}$ & $(0.032,0.049,0.067)$ & $(0.008,0.013,0.018)$ \\
$\mathrm{C}_{16}$ & $(0.049,0.071,0.100)$ & $(0.028,0.046,0.070)$ \\
\hline
\end{tabular}

Table 12 Similarity, distance, and integrated closeness index values for each supplier

\begin{tabular}{lllll}
\hline Supplier & $\bar{R}_{i}$ & $\bar{D}_{i}$ & $C S_{i}$ & Rank \\
\hline $\mathrm{A}_{1}$ & 0.446 & 0.393 & 0.430 & 4 \\
$\mathrm{~A}_{2}$ & 0.486 & 0.485 & 0.486 & 3 \\
$\mathrm{~A}_{3}$ & 0.517 & 0.642 & 0.580 & 2 \\
$\mathrm{~A}_{4}$ & 0.460 & 0.380 & 0.420 & 6 \\
$\mathrm{~A}_{5}$ & 0.480 & 0.378 & 0.429 & 5 \\
$\mathrm{~A}_{6}$ & 0.554 & 0.711 & 0.633 & 1 \\
\hline
\end{tabular}

with $\Sigma_{c}^{o}$ being the sum of the original values of the weights of criteria.

$\Delta x$ measures the amount of change applied to a set of weight coefficients depending on their weight elasticity coefficients. The changes in the weight of the most important criterion should be limited not to lead to negative weights, which would violate the weight proportionality limits. The parameter $\Delta x$ may be either positive or negative, indicating either an increase or a decrease in relative importance, respectively. As shown above, the limits for $\Delta x$ are defined as the largest changes in weight of the most important criterion in both the negative and positive direction.

After determining the limit values for $\Delta x$, the new weights of the criteria are calculated according to the pre-set parameters for sensitivity analysis. A set of new weights are calculated by using the following equations:

$w_{s}=w_{s}^{o}+(\Delta x) \alpha_{s}$

$w_{c}=w_{c}^{o}-(\Delta x) \alpha_{c}$

$\alpha_{s}$ represents the elasticity weight coefficient of the most important criterion, $w_{c}$ represents the changes in the weights of the criteria in the sensitivity analysis, and $w_{s}$ represents the changes in weight of the most important criterion. This new set of weights must satisfy the condition $\sum w_{s}+\sum w_{c}=1$.

After obtaining the interval of variation for the weight coefficients of $\mathrm{C}_{5}$, that is, $[-0.135,0.866]$, the new weights of all the other criteria are computed using the following equation:

Table 13 New criteria's weights according to the different scenarios

\begin{tabular}{|c|c|c|c|c|c|c|c|c|c|c|c|c|c|c|c|c|}
\hline \multirow[b]{2}{*}{ Criteria } & \multicolumn{16}{|c|}{ Global crisp w } \\
\hline & S1 & $\mathrm{S} 2$ & S3 & S4 & S5 & S6 & S7 & S8 & S9 & S10 & S11 & S12 & S13 & S14 & S15 & S16 \\
\hline $\mathrm{C}_{1}$ & 065 & 061 & 0.057 & 0.053 & 0.049 & 0.045 & 0.040 & 0.036 & 0.032 & 0.028 & 0.024 & 0.020 & 0.016 & 0.012 & 0.008 & 0.004 \\
\hline $\mathrm{C}_{2}$ & 031 & 0.029 & 0.027 & 0.025 & 0.023 & 0.021 & 0.020 & 0.018 & 0.016 & 0.014 & 0.012 & 0.010 & 0.008 & 0.006 & 0.004 & 0.002 \\
\hline $\mathrm{C}_{3}$ & 0.032 & 0.030 & 0.028 & 0.026 & 0.024 & 0.022 & 0.020 & 0.018 & 0.016 & 0.014 & 0.012 & 0.010 & 0.008 & 0.006 & 0.004 & 0.002 \\
\hline $\mathrm{C}_{4}$ & 0.061 & 0.057 & 0.054 & 0.050 & 0.046 & 0.042 & 0.038 & 0.034 & 0.031 & 0.027 & 0.023 & 0.019 & 0.015 & 0.011 & 0.008 & 0.004 \\
\hline $\mathrm{C}_{5}$ & 000 & 0.063 & 0.125 & 0.188 & 0.250 & 0.313 & 0.375 & 0.438 & 0.501 & 0.563 & 0.626 & 0.688 & 0.751 & 0.813 & 0.876 & 0.938 \\
\hline $\mathrm{C}_{6}$ & 0.064 & 0.060 & 0.056 & 0.052 & 0.048 & 0.044 & 0.040 & 0.036 & 0.032 & 0.028 & 0.024 & 0.020 & 0.016 & 0.012 & 0.008 & 0.004 \\
\hline $\mathrm{C}_{7}$ & .127 & 0.119 & 0.111 & 0.103 & 0.095 & 0.087 & 0.079 & 0.072 & 0.064 & 0.056 & 0.048 & 0.040 & 0.032 & 0.024 & 0.016 & 0.008 \\
\hline $\mathrm{C}_{8}$ & 0.101 & 0.094 & 0.088 & 0.082 & 0.075 & 0.069 & 0.063 & 0.057 & 0.050 & 0.044 & 0.038 & 0.031 & 0.025 & 0.019 & 0.013 & 0.006 \\
\hline $\mathrm{C}_{9}$ & 0.052 & 0.049 & 0.046 & 0.042 & 0.039 & 0.036 & 0.033 & 0.029 & 0.026 & 0.023 & 0.020 & 0.016 & 0.013 & 0.010 & 0.007 & 0.003 \\
\hline $\mathrm{C}_{10}$ & 0.045 & 0.042 & 0.039 & 0.037 & 0.034 & 0.031 & 0.028 & 0.025 & 0.023 & 0.020 & 0.017 & 0.014 & 0.011 & 0.008 & 0.006 & 0.003 \\
\hline $\mathrm{C}_{11}$ & 0.050 & 0.047 & 0.043 & 0.040 & 0.037 & 0.034 & 0.031 & 0.028 & 0.025 & 0.022 & 0.019 & 0.016 & 0.012 & 0.009 & 0.006 & 0.003 \\
\hline $\mathrm{C}_{12}$ & 0.018 & 0.017 & 0.016 & 0.015 & 0.014 & 0.013 & 0.012 & 0.010 & 0.009 & 0.008 & 0.007 & 0.006 & 0.005 & 0.003 & 0.002 & 0.001 \\
\hline $\mathrm{C}_{13}$ & 0.079 & 0.074 & 0.069 & 0.064 & 0.059 & 0.054 & 0.049 & 0.044 & 0.039 & 0.034 & 0.029 & 0.025 & 0.020 & 0.015 & 0.010 & 0.005 \\
\hline $\mathrm{C}_{14}$ & 0.114 & 0.107 & 0.100 & 0.093 & 0.086 & 0.079 & 0.072 & 0.064 & 0.057 & 0.050 & 0.043 & 0.036 & 0.029 & 0.021 & 0.014 & 0.007 \\
\hline $\mathrm{C}_{15}$ & 0.065 & 0.061 & 0.057 & 0.053 & 0.049 & 0.045 & 0.040 & 0.036 & 0.032 & 0.028 & 0.024 & 0.020 & 0.016 & 0.012 & 0.008 & 0.004 \\
\hline $\mathrm{C}_{16}$ & 0.097 & 0.091 & 0.085 & 0.079 & 0.073 & 0.067 & 0.061 & 0.055 & 0.049 & 0.042 & 0.036 & 0.030 & 0.024 & 0.018 & 0.012 & 0.006 \\
\hline
\end{tabular}


Fig. 2 The effect of criteria weight changes on the ranking of suppliers

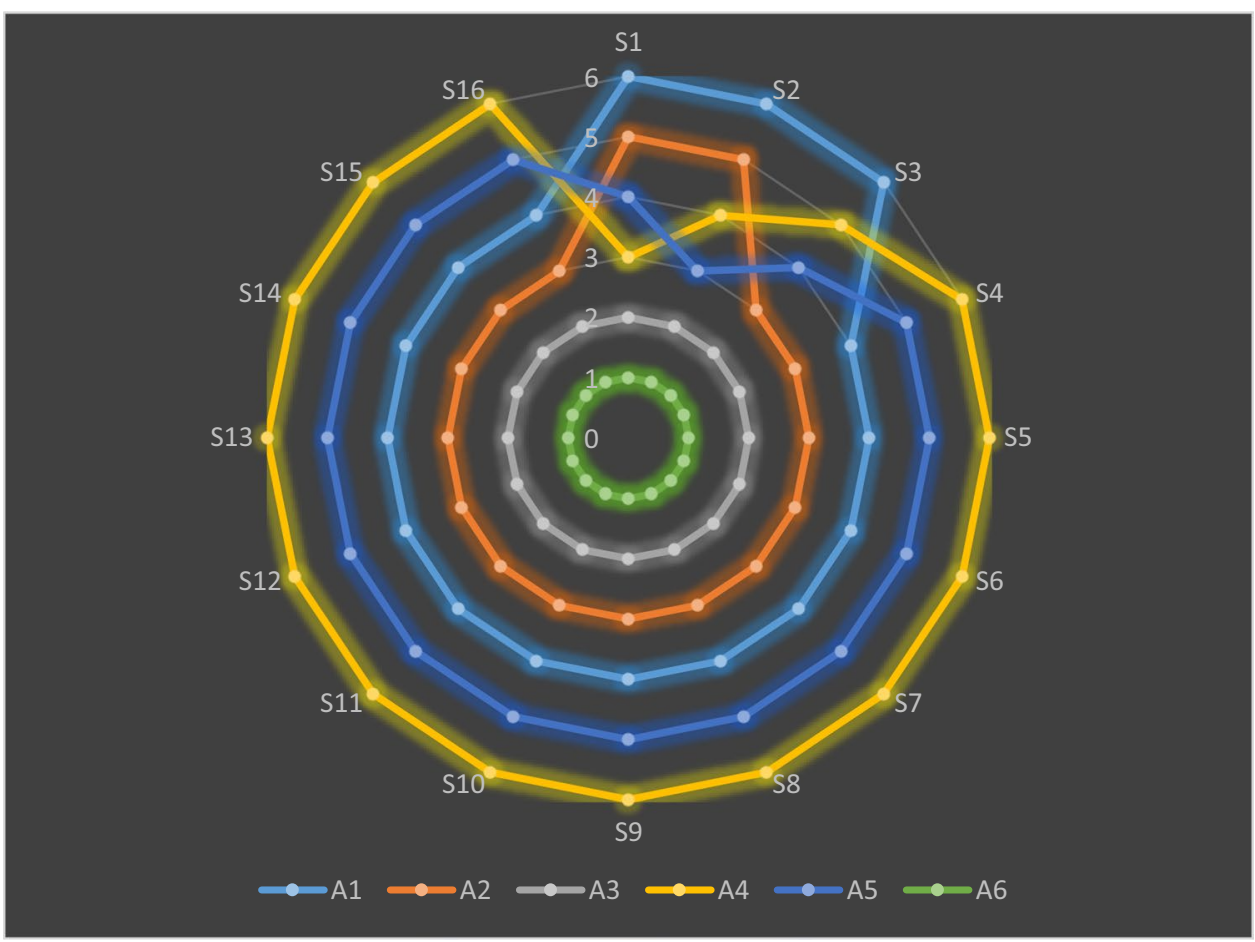

$w_{c}=\left(1-w_{s}\right)\left(\begin{array}{c}w_{c}^{o} / \Sigma_{c}^{o} \\ \end{array}\right)=w_{c}^{o}-(\Delta x) \alpha_{c}$

Equation (29) is applied to compute the entries of the columns of Table 13. Each column displays the changing weights of the criteria based on the elasticity coefficients for the corresponding scenario.

\section{Changing the components of the principal decision matrix}

One way of inducing inner changes in the decision matrix and, consequently, variations in the final priorities consists of adding or deleting a new alternative and/or a new criterion. In this section, we describe the sensitivity analysis performed on the results obtained in the case study by varying the number of alternatives (suppliers) in the principal matrix on the basis of a series of experiments. In each experiment, a condition is set to remove the worse alternative from subsequent calculations, while the remaining alternatives are ranked.

In the initial solution, supplier $\mathrm{A}_{4}$ was recognized as the worst one (experiment E0). Hence, $\mathrm{A}_{4}$ was removed from subsequent calculations. After removing $\mathrm{A}_{4}$, a new ranking of suppliers was created by running experiment $\mathrm{E} 1$. The new ranking generated within $\mathrm{E} 1$ was $\mathrm{A}_{6}>\mathrm{A}_{3}>\mathrm{A}_{2}>\mathrm{A}_{1}>\mathrm{A}_{5}$, indicating still $\mathrm{A}_{6}$ as the best supplier while $\mathrm{A}_{1}$ became the worst one. $A_{1}$ was removed, and the next experiment was run. The results of all the experiments are reported in Table 14.

Considering the information provided by Table 5 , the fact that there has been no change in the ranking of the best alternative was expected. Indeed, $\mathrm{A}_{6}$ remained the bestranked supplier through all the experiments, which confirms the stability and validity of the results obtained from the proposed FBWM-fuzzy GRA-TOPSIS model.

\section{Comparing the results with those of other fuzzy MCDM models}

Another valid method for analyzing the outcomes of a decision model is to compare them with those returned by using other known and effective techniques. This section compares the results obtained via the proposed fuzzy GRA-TOPSIS model with those of four renowned fuzzy MCDM methods, that is, fuzzy WASPAS (Turskis et al. 2015), fuzzy multi-objective optimization method by ratio analysis (MOORA) (Akkaya et al. 2015), fuzzy Evaluation based on distance from average solution (EDAS) (Ghorabaee et al. 2018), and modified fuzzy VIKOR (Liu et al. 2015). A visual comparison of all the rankings obtained for the suppliers implementing these fuzzy MCDM methods is shown in Fig. 3.

As shown in Fig. 3, suppliers $\mathrm{A}_{6}$ and $\mathrm{A}_{3}$ are the best-performing ones in all methods. Supplier $\mathrm{A}_{6}$ is ranked first according to the fuzzy GRA-TOPSIS, F-WASPAS, F-MOORA, and F-VIKOR methods. In contrast, supplier $\mathrm{A}_{3}$ is ranked first only by the F-EDAS method. Also, in all methods, supplier $\mathrm{A}_{2}$ is ranked third. Moreover, only a few minor changes in the ranking of suppliers $A_{1}, A_{4}$, and $A_{5}$ occur. For example, $A_{4}$ is assigned the worst performance by Fuzzy GRA-TOPSIS and F-VIKOR, but in other methods, the worst performance belongs to $A_{1}$.

Finally, the Spearman correlation coefficients were computed to determine the statistical significance of the differences amongst the 
Table 14 The arrange of suppliers

\begin{tabular}{ll}
\hline Experiment & Priority \\
\hline E0 & $\mathrm{A}_{6}>\mathrm{A}_{3}>\mathrm{A}_{2}>\mathrm{A}_{1}>\mathrm{A}_{5}>\mathrm{A}_{4}$ \\
E1 & $\mathrm{A}_{6}>\mathrm{A}_{3}>\mathrm{A}_{2}>\mathrm{A}_{5}>\mathrm{A}_{1}$ \\
E2 & $\mathrm{A}_{6}>\mathrm{A}_{3}>\mathrm{A}_{2}>\mathrm{A}_{5}$ \\
E3 & $\mathrm{A}_{6}>\mathrm{A}_{3}>\mathrm{A}_{2}$ \\
E4 & $\mathrm{A}_{6}>\mathrm{A}_{3}$ \\
E5 & $\mathrm{A}_{6}$ \\
\hline
\end{tabular}

rankings generated by the different methods. According to Si et al. (2019), a value larger than 0.7 for the correlation coefficient indicates a high relationship. In the implemented experiments, all values of correlation coefficients were larger than 0.7 , with a mean value of 0.840 . Table 15 shows the correlation coefficients resulting from comparing the rankings produced by the different methods and highlights the strong correlation existing among them. As a consequence, it can be concluded that the proposed ranking method is reliable.

\section{Conclusion and scope of future work}

In this study, a new fuzzy MCDM approach has been proposed to evaluate suppliers with respect to sustainable and resilient criteria, and a real-life case study was conducted in the main company active in producing sanitary and industrial valves.
The presented framework consists of four main phases. First, an expert committee familiar with supplier selection problems is selected. After an extensive review of the existing literature, also considering experts' opinions, supplier evaluation indicators are identified and categorized into four main criteria (economic, environmental, social, and resilient) and 16 sub-criteria. In addition, a set of qualified suppliers are identified. In the case study, the evaluating team was formed by three experts while there were six suppliers to evaluate.

In the second phase, the best and worst criteria and subcriteria are determined through a collective agreement among the experts, and after assigning the subjective preferences of experts, the final weights of the criteria and subcriteria are calculated by solving the nonlinear mathematical programming model defined within the FBWM. In the case study, "pollution control," "environmental management system," and "risk awareness" turned out to be the most effective evaluation criteria.

In the third phase, the single suppliers are evaluated by applying a new decision-making approach based on the combination of GRA and TOPSIS methods within the fuzzy environment. Finally, in the fourth phase, a sensitivity analysis based on three different approaches is performed to validate the effectiveness of the proposed framework for SRSSPs and the reliability of the ranking results.

From the managerial viewpoint, the proposed framework offers both a technically sound and practically implementable method to solve SSPs within the current supply chain context, increasingly concerned with sustainability
Fig. 3 Comparison of the ranking results with those of other fuzzy MCDM methods

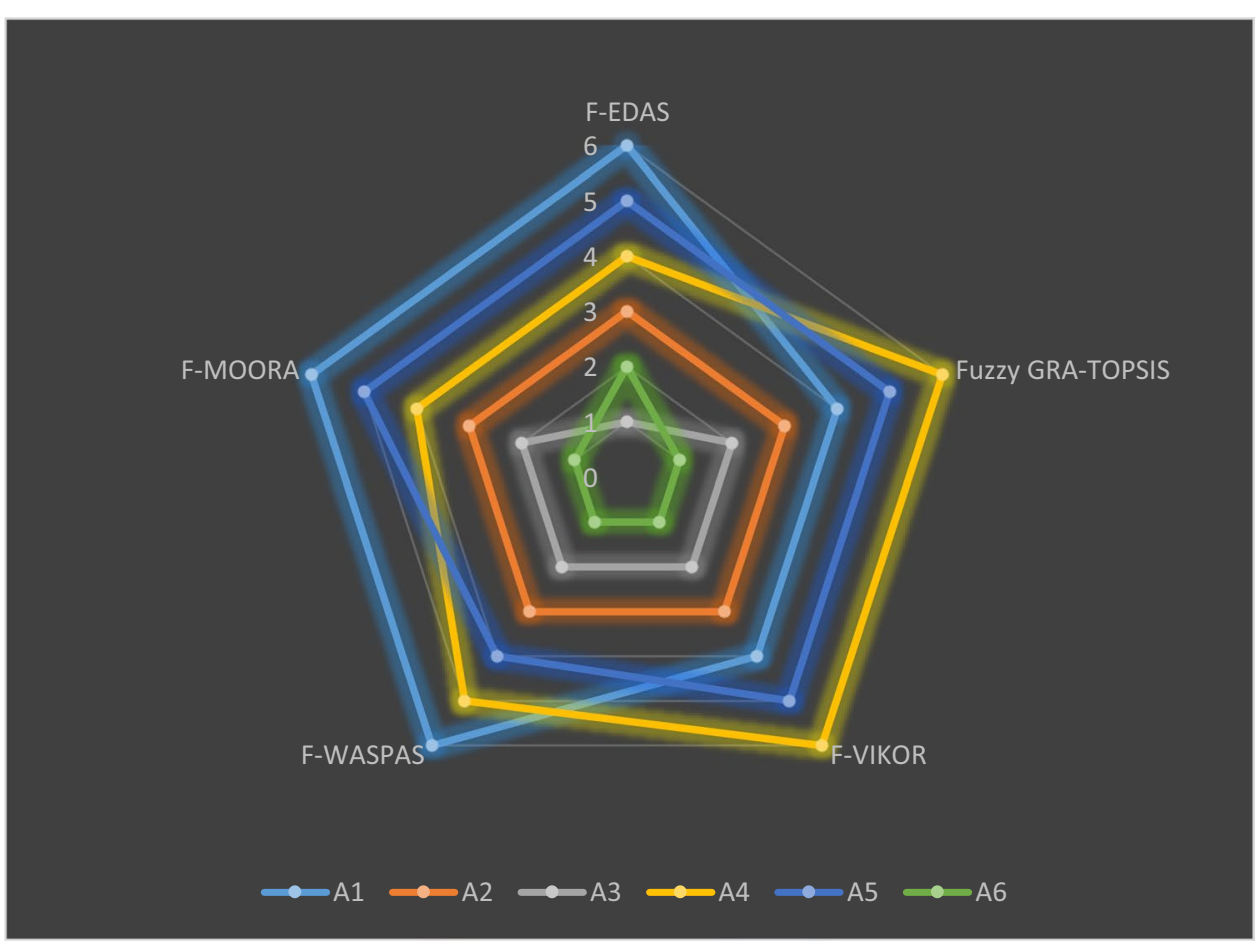


Table 15 Correlation coefficients of the examined techniques

\begin{tabular}{llllll}
\hline & $\begin{array}{l}\text { Fuzzy GRA- } \\
\text { TOPSIS }\end{array}$ & F-EDAS & F-VIKOR & F-WASPAS & F-MOORA \\
\hline Fuzzy GRA-TOPSIS & 1.000 & 0.714 & 1.000 & 0.829 & 0.771 \\
F-EDAS & & 1.000 & 0.714 & 0.886 & 0.943 \\
F-VIKOR & & 1.000 & 0.829 & 0.771 \\
F-WASPAS & & & 1.000 & 0.943 \\
F-MOORA & & & & 1.000 \\
\hline
\end{tabular}

and resilience issues. At the same time, the case study can be used as a guide by the managers of similar businesses to measure their suppliers' performance and analyze their supply chains. In the long term, implementing a reliable evaluation methodology like the one proposed in this study can help reduce costs, save resources, increase resilience, and reduce environmental impacts.

Future research could focus on combining the proposed approach with mathematical programming models to determine the optimal order allocation of suppliers.

Moreover, the current research could be expanded by developing the proposed approach using other types of fuzzy sets like intuitionistic fuzzy sets, hesitant fuzzy sets, and interval type-2 fuzzy sets. As an initial application of the proposed method, in this paper, TFNs were used to express the weights of criteria and alternatives so as to account for the ambiguity and uncertainty inherent to DMs' subjective evaluations. The choice of working with TFNs was motivated by their widespread use as a quantitative measure of linguistic evaluations. However, the proposed method can be easily extended to other fuzzy settings depending on the level of uncertainty managers, and experts must deal with. For example, apart from the uncertainty and imprecision of the available data, it may be necessary to consider the DMs' voting powers and/or how confident they are about their evaluations. In situations like this, an asymmetric measuring tool for linguistic preferences would allow for a more coherent interpretation of the different viewpoints of the different experts/DMs. In this sense, concrete applications of our method could be derived from using asymmetric interval type-2 triangular fuzzy sets (IT2TFSs). Not only asymmetric IT2TFSs are simpler to implement in real-life assessments than more involved fuzzy concepts such as hesitant and neutrosophic sets, but they could also be used to express the uncertainty deriving from the available data/information and the confidence levels of the experts simultaneously.

Acknowledgements Dr. Madjid Tavana is grateful for the partial support he received from the Czech Science Foundation (GA CR1913946S) for this research.

Author contribution Ahmadreza Afrasiabi: conceptualization, methodology, formal analysis, and writing-original draft; Madjid Tavana: conceptualization, methodology, formal analysis, writing-review and editing, and visualization; Debora Di Caprio: methodology, formal analysis, investigation, validation, and writing-review and editing.

Funding Dr. Madjid Tavana is grateful for the partial support he received from the Czech Science Foundation (GACR19-13946S) for this research.

Data availability Not applicable.

Declaration

Ethics approval Not applicable.

Consent to participate Not applicable.

Consent for publication Not applicable.

Competing interests The authors declare no competing interests.

\section{References}

Abdullah L, Chan W, Afshari A (2019) Application of PROMETHEE method for green supplier selection: a comparative result based on preference functions. J Ind Eng Int 15(2):271-285

Ahi P, Searcy C (2013) A comparative literature analysis of definitions for green and sustainable supply chain management. J Clean Prod $52: 329-341$

Akkaya G, Turanoğlu B, Öztaş S (2015) An integrated fuzzy AHP and fuzzy MOORA approach to the problem of industrial engineering sector choosing. Expert Syst Appl 42(24):9565-9573

Alamroshan F, La'li M, \& Yahyaei M (2021). The green-agile supplier selection problem for the medical devices: a hybrid fuzzy decision-making approach. Environ Sci Pollut Res 1-19.

Amid A, Ghodsypour S, O'Brien C (2006) Fuzzy multiobjective linear model for supplier selection in a supply chain. Int J Prod Econ 104(2):394-407

Amindoust A (2018a) A resilient-sustainable based supplier selection model using a hybrid intelligent method. Comput Ind Eng 126:122-135

Amindoust A (2018b) Supplier selection considering sustainability measures: an application of weight restriction fuzzy-DEA approach. RAIRO-Oper Res 52(3):981-1001

Amindoust A, Ahmed S, Saghafinia A, Bahreininejad A (2012) Sustainable supplier selection: a ranking model based on fuzzy inference system. Appl Soft Comput 12(6):1668-1677

Amiri M, Hashemi-Tabatabaei M, Ghahremanloo M, Keshavarz-Ghorabaee M, Zavadskas E, Banaitis A (2021) A new fuzzy BWM 
approach for evaluating and selecting a sustainable supplier in supply chain management. Int J Sustain Dev World Ecol 28(2):125-142

Ansari ZN, Kant R, Shankar R (2020) Evaluation and ranking of solutions to mitigate sustainable remanufacturing supply chain risks: a hybrid fuzzy SWARA-fuzzy COPRAS framework approach. Int J Sustain Eng 13(6):473-494

Awasthi A, Kannan G (2016) Green supplier development program selection using NGT and VIKOR under fuzzy environment. Comput Ind Eng 91:100-108

Babbar C, Amin SH (2018) A multi-objective mathematical model integrating environmental concerns for supplier selection and order allocation based on fuzzy QFD in beverages industry. Expert Syst Appl 92:27-38

Badi I, Ballem M (2018) Supplier selection using the rough BWMMAIRCA model: a case study in pharmaceutical supplying in Libya. Decision Making: Applications in Management and Engineering 1(2):16-33

Banaeian N, Mobli H, Fahimnia B, Nielsen IE, Omid M (2018) Green supplier selection using fuzzy group decision making methods: a case study from the agri-food industry. Comput Oper Res 89:337-347

Bansal P, DesJardine MR (2014) Business sustainability: it is about time. Strateg Organ 12(1):70-78

Behzad M, Zolfani SH, Pamucar D, Behzad M (2020) A comparative assessment of solid waste management performance in the Nordic countries based on BWM-EDAS. J Clean Prod 266:122008

Behzadi G, O'Sullivan MJ, Olsen TL (2020) On metrics for supply chain resilience. Eur J Oper Res 287(1):145-158

Chaabane A, Ramudhin A, Paquet M (2012) Design of sustainable supply chains under the emission trading scheme. Int J Prod Econ 135(1):37-49

Chen C-T (2000) Extensions of the TOPSIS for group decision-making under fuzzy environment. Fuzzy Sets Syst 114(1):1-9

Chen Z, Ming X, Zhou T, Chang Y (2020) Sustainable supplier selection for smart supply chain considering internal and external uncertainty: an integrated rough-fuzzy approach. Appl Soft Comput 87:106004

Closs DJ, Speier C, Meacham N (2011) Sustainability to support endto-end value chains: the role of supply chain management. J Acad Mark Sci 39(1):101-116

Davoudabadi R, Mousavi SM, Mohagheghi V, Vahdani B (2019) Resilient supplier selection through introducing a new interval-valued intuitionistic fuzzy evaluation and decision-making framework. Arab J Sci Eng 44(8):7351-7360

Davoudabadi R, Mousavi SM, Sharifi E (2020) An integrated weighting and ranking model based on entropy, DEA and PCA considering two aggregation approaches for resilient supplier selection problem. J Comput Sci 40:101074

Deng J-L (1982) Control problems of grey systems. Syst Control Lett 1(5):288-294

Fahimnia B, Jabbarzadeh A (2016) Marrying supply chain sustainability and resilience: a match made in heaven. Transp Res Part E: Logist Transp Rev 91:306-324

Fallahpour A, Nayeri S, Sheikhalishahi M, Wong KY, Tian G, \& Fathollahi-Fard AM (2021). A hyper-hybrid fuzzy decisionmaking framework for the sustainable-resilient supplier selection problem: a case study of Malaysian palm oil industry. Environ Sci Pollut Res 1-21.

Fox-Lent C, Bates ME, Linkov I (2015) A matrix approach to community resilience assessment: an illustrative case at Rockaway Peninsula. Environ Syst Decisions 35(2):209-218

Geum Y, Cho Y, Park Y (2011) A systematic approach for diagnosing service failure: service-specific FMEA and grey relational analysis approach. Math Comput Model 54(11-12):3126-3142

Ghorabaee MK, Amiri M, Zavadskas EK, Antucheviciene J (2018) A new hybrid fuzzy MCDM approach for evaluation of construction equipment with sustainability considerations. Arch Civil Mech Eng 18:32-49

Ghoushchi SJ, Milan MD, Rezaee MJ (2018) Evaluation and selection of sustainable suppliers in supply chain using new GP-DEA model with imprecise data. J Ind Eng Int 14(3):613-625

Golan MS, Jernegan LH, Linkov I (2020) Trends and applications of resilience analytics in supply chain modeling: systematic literature review in the context of the COVID-19 pandemic. Environ Syst Decisions 40:222-243

Guo S, Zhao H (2017) Fuzzy best-worst multi-criteria decision-making method and its applications. Knowl-Based Syst 121:23-31

Gupta H, Barua MK (2017) Supplier selection among SMEs on the basis of their green innovation ability using BWM and fuzzy TOPSIS. J Clean Prod 152:242-258

Gupta S, Soni U, Kumar G (2019) Green supplier selection using multicriterion decision making under fuzzy environment: a case study in automotive industry. Comput Ind Eng 136:663-680

Haeri SAS, Rezaei J (2019) A grey-based green supplier selection model for uncertain environments. J Clean Prod 221:768-784

Handfield R, Walton SV, Sroufe R, Melnyk SA (2002) Applying environmental criteria to supplier assessment : a study in the application of the Analytical Hierarchy Process. Eur J Oper Res 141(1):70-87

Hollnagel E, Paries J, Woods DD, Wreathall J (eds) (2013) Resilience engineering in practice: a guidebook. Ashgate Publishing, Ltd, London

Hosseini S, Al Khaled A (2019) A hybrid ensemble and AHP approach for resilient supplier selection. J Intell Manuf 30(1):207-228

Humphreys PK, Wong YK, Chan FTS (2003) Integrating environmental criteria into the supplier selection process. J Mater Process Technol 138(1):349-356

Humphreys P, McCloskey A, McIvor R, Maguire L, Glackin C (2006) Employing dynamic fuzzy membership functions to assess environmental performance in the supplier selection process. Int J Prod Res 44(12):2379-2419

Hwang C-L, Yoon K (1981) Methods for multiple attribute decision making multiple attribute decision making. Springer, Berlin, pp 58-191

Jain N, Singh A (2020) Sustainable supplier selection under mustbe criteria through fuzzy inference system. J Clean Prod 248:119275

Kahraman YR (2002). Robust sensitivity analysis for multi-attribute deterministic hierarchical value models. Air Force Inst of Tech Wright-Pattersonafb $\mathrm{OH}$.

Kamalahmadi M, Parast MM (2016) A review of the literature on the principles of enterprise and supply chain resilience: major findings and directions for future research. Int J Prod Econ 171:116-133

Kannan D, Govindan K, Rajendran S (2015) Fuzzy axiomatic design approach based green supplier selection: a case study from Singapore. J Clean Prod 96:194-208

Khor KS, Udin ZM (2013) Reverse logistics in Malaysia: investigating the effect of green product design and resource commitment. Resour Conserv Recycl 81:71-80

Kim G, Park CS, Yoon KP (1997) Identifying investment opportunities for advanced manufacturing systems with comparative-integrated performance measurement. Int J Prod Econ 50(1):23-33

Kirkwood CW (1997) Strategic decision making. Duxbury Press, Belmont, p 149

Kuo M-S, Liang G-S (2011) Combining VIKOR with GRA techniques to evaluate service quality of airports under fuzzy environment. Expert Syst Appl 38(3):1304-1312

Kwak DW, Seo YJ, Mason R (2018) Investigating the relationship between supply chain innovation, risk management capabilities 
and competitive advantage in global supply chains. Int J Oper Prod Manag 38(1):2-21

Lee S, Kang D (2019) Development of interval-valued fuzzy GRA with SERVPERF based on subjective and objective weights for evaluation of airline service quality: a case study of Korea lowcost carriers. PLoS One 14(8):1-27

Lee J, Cho H, Kim YS (2015) Assessing business impacts of agility criterion and order allocation strategy in multi-criteria supplier selection. Expert Syst Appl 42(3):1136-1148

Li G-D, Yamaguchi D, Nagai M (2007) A grey-based decision-making approach to the supplier selection problem. Math Comput Model 46(3-4):573-581

Li G-D, Yamaguchi D, Nagai M (2008) A grey-based rough decisionmaking approach to supplier selection. Int J Adv Manuf Technol 36(9-10): 1032

Li F, Wu C-H, Zhou L, Xu G, Liu Y, Tsai S-B (2021) A model integrating environmental concerns and supply risks for dynamic sustainable supplier selection and order allocation. Soft Comput 25(1):535-549

Liao M-S, Liang G-S, Chen C-Y (2013) Fuzzy grey relation method for multiple criteria decision-making problems. Qual Quant 47(6):3065-3077

Linkov I, Trump BD (2019) The science and practice of resilience. Springer International Publishing, Cham

Linkov I, Eisenberg DA, Bates ME, Chang D, Convertino M, Allen JH, Seager TP (2013a) Measurable resilience for actionable policy. Environ Sci Technol 47(18):10108-10110

Linkov I, Eisenberg DA, Plourde K, Seager TP, Allen J, Kott A (2013b) Resilience metrics for cyber systems. Environ Syst Decisions 33(4):471-476

Linkov I, Fox-Lent C, Read L, Allen CR, Arnott JC, Bellini E, Coaffee J, Florin M-V, Hatfield K, Hyde I, Hynes W, Jovanovic A, Kasperson R, Katzenberger J, Keys PW, Lambert JH, Moss R, Murdoch PS, Palma-Oliveira J et al (2018a) Tiered approach to resilience assessment. Risk Anal 38(9):1772-1780

Linkov I, Trump BD, Keisler J (2018b) Don't conflate risk and resilience. Nature 555(7694):27-27

Linkov I, Moberg E, Trump BD, Yatsalo B, Keisler JM (2021) Multicriteria decision analysis: case studies in engineering and the environment. CRC Press, Boca Raton

Liu H-C, You J-X, You X-Y, Shan M-M (2015) A novel approach for failure mode and effects analysis using combination weighting and fuzzy VIKOR method. Appl Soft Comput 28:579-588

Lo H-W, Liou JJ, Wang H-S, Tsai Y-S (2018) An integrated model for solving problems in green supplier selection and order allocation. J Clean Prod 190:339-352

Mafakheri F, Breton M, Ghoniem A (2011) Supplier selection-order allocation: a two-stage multiple criteria dynamic programming approach. Int J Prod Econ 132(1):52-57

Mahmoudi A, Deng X, Javed SA, Zhang N (2021a) Sustainable supplier selection in megaprojects: grey ordinal priority approach. Bus Strateg Environ 30(1):318-339

Mahmoudi A, Javed SA, \& Mardani A (2021b). Gresilient supplier selection through fuzzy ordinal priority approach: decisionmaking in post-COVID era. Oper Manag Res 1-25.

Marchese D, Reynolds E, Bates ME, Morgan H, Clark SS, Linkov I (2018) Resilience and sustainability: similarities and differences in environmental management applications. Sci Total Environ 613:1275-1283

Memari A, Dargi A, Jokar MRA, Ahmad R, Rahim ARA (2019) Sustainable supplier selection: a multi-criteria intuitionistic fuzzy TOPSIS method. J Manuf Syst 50:9-24

Mohammed A, Harris I, Soroka A, Naim M, Ramjaun T, Yazdani M (2021) Gresilient supplier assessment and order allocation planning. Ann Oper Res 296(1):335-362
Moheb-Alizadeh H, Handfield R (2019) Sustainable supplier selection and order allocation: a novel multi-objective programming model with a hybrid solution approach. Comput Ind Eng 129:192-209

Nayeri S, Paydar MM, Asadi-Gangraj E, Emami S (2020) Multiobjective fuzzy robust optimization approach to sustainable closed-loop supply chain network design. Comput Ind Eng 148:106716

Nayeri S, Tavakoli M, Tanhaeean M, \& Jolai F (2021). A robust fuzzy stochastic model for the responsive-resilient inventory-location problem: comparison of metaheuristic algorithms. Ann Oper Res $1-41$.

Nazari-Shirkouhi S, Shakouri H, Javadi B, Keramati A (2013) Supplier selection and order allocation problem using a two-phase fuzzy multi-objective linear programming. Appl Math Model 37(22):9308-9323

Orji IJ, Wei S (2015) An innovative integration of fuzzy-logic and systems dynamics in sustainable supplier selection: a case on manufacturing industry. Comput Ind Eng 88:1-12

Oztaysi B (2014) A decision model for information technology selection using AHP integrated TOPSIS-Grey: the case of content management systems. Knowl-Based Syst 70:44-54

Park J, Seager TP, Rao PSC, Convertino M, Linkov I (2013) Integrating risk and resilience approaches to catastrophe management in engineering systems. Risk Anal 33(3):356-367

Parkouhi SV, Ghadikolaei AS (2017) A resilience approach for supplier selection: using fuzzy analytic network process and grey VIKOR techniques. J Clean Prod 161:431-451

Parkouhi SV, Ghadikolaei AS, Lajimi HF (2019) Resilient supplier selection and segmentation in grey environment. J Clean Prod 207:1123-1137

Rabbani M, Foroozesh N, Mousavi SM, Farrokhi-Asl H (2019) Sustainable supplier selection by a new decision model based on interval-valued fuzzy sets and possibilistic statistical reference point systems under uncertainty. Int J Syst Sci: Oper Logist 6(2):162-178

Rajesh R, Ravi V (2015) Supplier selection in resilient supply chains: a grey relational analysis approach. J Clean Prod 86:343-359

Roege PE, Collier ZA, Mancillas J, McDonagh JA, Linkov I (2014) Metrics for energy resilience. Energy Policy 72:249-256

Saaty TL (2000) Fundamentals of decision making and priority theory with the analytic hierarchy process, 6th edn. RWS publications, Pittsburgh

Sarkis J, Dhavale DG (2015) Supplier selection for sustainable operations: a triple-bottom-line approach using a Bayesian framework. Int J Prod Econ 166:177-191

Sazvar Z, Zokaee M, Tavakkoli-Moghaddam R, Salari SA-S, \& Nayeri S (2021). Designing a sustainable closed-loop pharmaceutical supply chain in a competitive market considering demand uncertainty, manufacturer's brand and waste management. Ann Oper Res 1-32.

Sen DK, Datta S, Mahapatra SS (2017) Dominance based fuzzy decision support framework for g-resilient (ecosilient) supplier selection: an empirical modelling. Int J Sustain Eng 10(6):338-357

Si A, Das S, Kar S (2019) An approach to rank picture fuzzy numbers for decision making problems. Decision Making: Applications in Management and Engineering 2(2):54-64

Sindhu S, Nehra V, Luthra S (2017) Investigation of feasibility study of solar farms deployment using hybrid AHP-TOPSIS analysis: case study of India. Renew Sust Energ Rev 73:496-511

Singh S, Olugu EU, Fallahpour A (2014) Fuzzy-based sustainable manufacturing assessment model for SMEs. Clean Techn Environ Policy 16(5):847-860

Stević Ž, Pamučar D, Puška A, Chatterjee P (2020) Sustainable supplier selection in healthcare industries using a new MCDM 
method: measurement of alternatives and ranking according to compromise solution (MARCOS). Comput Ind Eng 140:106231

Tavana M, Shaabani A, Di Caprio D, Bonyani A (2021a) An integrated group fuzzy best-worst method and combined compromise solution with Bonferroni functions for supplier selection in reverse supply chains. Clean Logist Supply Chain 2:100009

Tavana M, Shaabani A, Santos-Arteaga FJ, \& Valaei N (2021b). An integrated fuzzy sustainable supplier evaluation and selection framework for green supply chains in reverse logistics. Environ Sci Pollut Res 1-30.

Thomas A, Byard P, Francis M, Fisher R, White Gareth RT (2016) Profiling the resiliency and sustainability of UK manufacturing companies. J Manuf Technol Manag 27(1):82-99

Tian G, Zhang H, Feng Y, Wang D, Peng Y, Jia H (2018a) Green decoration materials selection under interior environment characteristics: a grey-correlation based hybrid MCDM method. Renew Sust Energ Rev 81:682-692

Tian G, Zhang H, Zhou M, Li Z (2018b) AHP, gray correlation, and TOPSIS combined approach to green performance evaluation of design alternatives. IEEE Trans Syst Man Cybernet: Systems 48(7):1093-1105

Tian Z-P, Wang J-Q, Zhang H-Y (2018c) An integrated approach for failure mode and effects analysis based on fuzzy best-worst, relative entropy, and VIKOR methods. Appl Soft Comput 72:636-646

Tirkolaee EB, Mardani A, Dashtian Z, Soltani M, Weber G-W (2020) A novel hybrid method using fuzzy decision making and multiobjective programming for sustainable-reliable supplier selection in two-echelon supply chain design. J Clean Prod 250:119517

Torabi S, Baghersad M, Mansouri S (2015) Resilient supplier selection and order allocation under operational and disruption risks. Transp Res Part E: Logist Transp Rev 79:22-48
Turskis Z, Zavadskas EK, Antucheviciene J, Kosareva N (2015) A hybrid model based on fuzzy AHP and fuzzy WASPAS for construction site selection. Int J Comp Commun Control 10(6):113-128

Vasiljević M, Fazlollahtabar H, Stević Ž, Vesković S (2018) A rough multi-criteria approach for evaluation of the supplier criteria in automotive industry. Decision Making: Applications in Management and Engineering 1(1):82-96

Whipple Judith M, Roh J (2010) Agency theory and quality fade in buyer-supplier relationships. Int J Logist Manag 21(3):338-352

Wu H-H (2002) A comparative study of using grey relational analysis in multiple attribute decision making problems. Qual Eng 15(2):209-217

Yao J-S, Wu K (2000) Ranking fuzzy numbers based on decomposition principle and signed distance. Fuzzy Sets Syst 116(2):275-288

Yazdani M, Chatterjee P, Zavadskas EK, Zolfani SH (2017) Integrated QFD-MCDM framework for green supplier selection. J Clean Prod 142:3728-3740

Yazdani M, Torkayesh Ali E, Chatterjee P (2020) An integrated decision-making model for supplier evaluation in public healthcare system: the case study of a Spanish hospital. J Enterp Inf Manag 33(5):965-989

Zadeh LA (1965) Fuzzy sets. Inf Control 8(3):338-353

Zailani S, Jeyaraman K, Vengadasan G, Premkumar R (2012) Sustainable supply chain management (SSCM) in Malaysia: a survey. Int J Prod Econ 140(1):330-340

Zhang S-F, Liu S-Y, Zhai R-H (2011) An extended GRA method for MCDM with interval-valued triangular fuzzy assessments and unknown weights. Comput Ind Eng 61(4):1336-1341

Zhao H, Guo S (2014) Selecting green supplier of thermal power equipment by using a hybrid MCDM method for sustainability. Sustainability 6(1):217-235

Publisher's note Springer Nature remains neutral with regard to jurisdictional claims in published maps and institutional affiliations. 